NASA/TM-2007-214947

\title{
Preliminary Structural Sizing and Alternative Material Trade Study of CEV Crew Module
}

Brett A. Bednarcyk

Ohio Aerospace Institute, Brook Park,Ohio

Steven M. Arnold

Glenn Research Center, Cleveland, Ohio

Craig S. Collier and Phillip W. Yarrington

Collier Research Corporation, Hampton, Virginia 


\section{NASA STI Program . . . in Profile}

Since its founding, NASA has been dedicated to the advancement of aeronautics and space science. The NASA Scientific and Technical Information (STI) program plays a key part in helping NASA maintain this important role.

The NASA STI Program operates under the auspices of the Agency Chief Information Officer. It collects, organizes, provides for archiving, and disseminates NASA's STI. The NASA STI program provides access to the NASA Aeronautics and Space Database and its public interface, the NASA Technical Reports Server, thus providing one of the largest collections of aeronautical and space science STI in the world. Results are published in both non-NASA channels and by NASA in the NASA STI Report Series, which includes the following report types:

- TECHNICAL PUBLICATION. Reports of completed research or a major significant phase of research that present the results of NASA programs and include extensive data or theoretical analysis. Includes compilations of significant scientific and technical data and information deemed to be of continuing reference value. NASA counterpart of peer-reviewed formal professional papers but has less stringent limitations on manuscript length and extent of graphic presentations.

- TECHNICAL MEMORANDUM. Scientific and technical findings that are preliminary or of specialized interest, e.g., quick release reports, working papers, and bibliographies that contain minimal annotation. Does not contain extensive analysis.

- CONTRACTOR REPORT. Scientific and technical findings by NASA-sponsored contractors and grantees.
- CONFERENCE PUBLICATION. Collected papers from scientific and technical conferences, symposia, seminars, or other meetings sponsored or cosponsored by NASA.

- SPECIAL PUBLICATION. Scientific, technical, or historical information from NASA programs, projects, and missions, often concerned with subjects having substantial public interest.

- TECHNICAL TRANSLATION. Englishlanguage translations of foreign scientific and technical material pertinent to NASA's mission.

Specialized services also include creating custom thesauri, building customized databases, organizing and publishing research results.

For more information about the NASA STI program, see the following:

- Access the NASA STI program home page at http://www.sti.nasa.gov

- E-mail your question via the Internet to help@sti.nasa.gov

- Fax your question to the NASA STI Help Desk at 301-621-0134

- Telephone the NASA STI Help Desk at 301-621-0390

- Write to: NASA Center for AeroSpace Information (CASI) 7115 Standard Drive Hanover, MD 21076-1320 


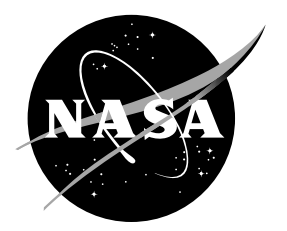

\section{Preliminary Structural Sizing and Alternative Material Trade Study of CEV Crew Module}

Brett A. Bednarcyk

Ohio Aerospace Institute, Brook Park, Ohio

Steven M. Arnold

Glenn Research Center, Cleveland, Ohio

Craig S. Collier and Phillip W. Yarrington

Collier Research Corporation, Hampton, Virginia

Prepared for the

48th Structures, Structural Dynamics, and Materials (SDM) Conference cosponsored by the AIAA, ASME, ASCE, AHS, and ASC

Honolulu, Hawaii, April 23-26, 2007

National Aeronautics and

Space Administration

Glenn Research Center

Cleveland, Ohio 44135 


\section{Acknowledgments}

The authors acknowledge the financial support of the 2006 NESC composite CM project, led by Michael Kirsch of the NESC and Thomas Gates of NASA Langley Research Center (LaRC). They also thank Robert Allen of ZIN Technologies for finite element analysis work on the monocoque CM concept, Ian Fernandez and Hiro Miura of NASA Ames Research Center (ARC) for providing the finite element model for the geometrically stiffened CM concept, and Winifred Feldhaus and David Sleight for providing the finite element model for the stiffened sandwich CM concept.

Trade names and trademarks are used in this report for identification only. Their usage does not constitute an official endorsement, either expressed or implied, by the National Aeronautics and Space Administration.

Level of Review: This material has been technically reviewed by technical management.

Available from

NASA Center for Aerospace Information 7115 Standard Drive

Hanover, MD 21076-1320
National Technical Information Service 5285 Port Royal Road Springfield, VA 22161 


\title{
Preliminary Structural Sizing and Alternative Material Trade Study for CEV Crew Module
}

\author{
Brett A. Bednarcyk \\ Ohio Aerospace Institute \\ Brook Park, Ohio 44142 \\ Steven M. Arnold \\ National Aeronautics and Space Administration \\ Glenn Research Center \\ Cleveland, Ohio 44135 \\ Craig S. Collier and Phillip W. Yarrington \\ Collier Research Corporation \\ Hampton, Virginia 23669
}

\begin{abstract}
This paper presents the results of a preliminary structural sizing and alternate material trade study for NASA's Crew Exploration Vehicle (CEV) Crew Module (CM). This critical CEV component will house the astronauts during ascent, docking with the International Space Station, reentry, and landing. The alternate material design study considers three materials beyond the standard metallic (aluminum alloy) design that resulted from an earlier NASA Smart Buyer Team analysis. These materials are graphite/epoxy composite laminates, discontinuously reinforced SiC/Al (DRA) composites, and a novel integrated panel material/concept known as WebCore. Using the HyperSizer (Collier Research and Development Corporation) structural sizing software and NASTRAN finite element analysis code, a comparison is made among these materials for the three composite CM concepts considered by the 2006 NASA Engineering and Safety Center Composite Crew Module project.
\end{abstract}

\section{Introduction}

In an effort to develop a strong in-house understanding of the design drivers for the CEV CM (see fig. 1), NASA formed a multi-center Smart Buyer Team in January 2006 to perform a preliminary design. This 10 week effort focused on a grid-stiffened aluminum-lithium (Al-Li) design with ring frames and longerons, but also considered composite materials through a simple material substitution. It was determined that composites could potentially deliver a 12 percent mass savings (ref. 1), with even greater mass savings possible through tailoring the overall design to composites. In order to pursue these additional mass savings, the NASA Engineering and Safety Center (NESC) formed a multi-center composite CM team to perform a preliminary design and characterize additional design drivers as they apply to composites, such as manufacturability, crashworthiness, damage tolerance, inspectability, reparability, and the effects of micro-meteoroid orbital debris (MMOD) impacts (ref. 2). This team concluded its work after four months, in September 2006. A second phase of the NESC composite CM project commenced in January 2007, with the goal of completing the design and fabrication of a composite CM in 18 months.

This paper presents the authors' contributions to the 2006 NESC composite CM project. These contributions primarily involve preliminary design trade studies among materials and panel concepts across the three major CM concepts investigated by the team (see fig. 2). The focus of the present paper is on identifying weight advantages, while other important design issues (manufacturability, inspectability, etc.) are not addressed herein. Trade studies were performed using the HyperSizer structural sizing software (ref. 3), in conjunction with the NASTRAN finite element analysis (FEA) software (ref. 4). 


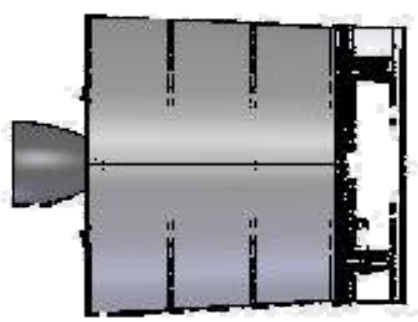

(a)

Service Module

$(\mathrm{SM})$

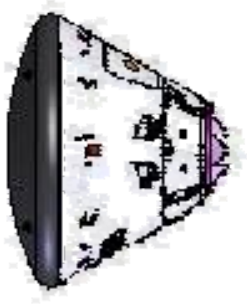

(b)

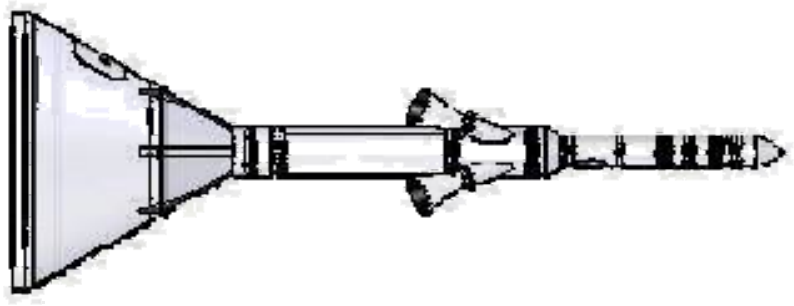

(c)

Launch Abort

System (LAS)

Figure 1.-Components comprising the upper stage of the Crew Exploration Vehicle: (a) Service module

(SM), (b) Crew module (CM), and (c) Launch Abort System (LAS).

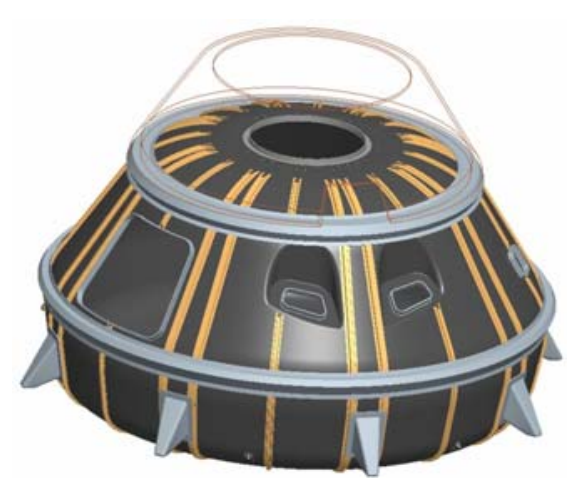

(a)

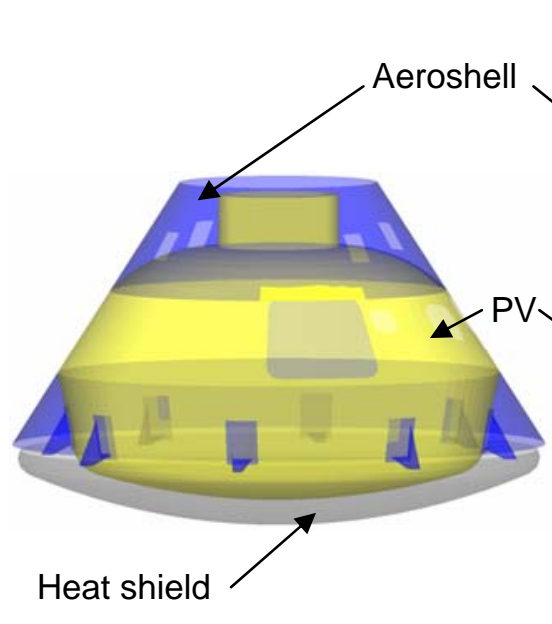

(b)

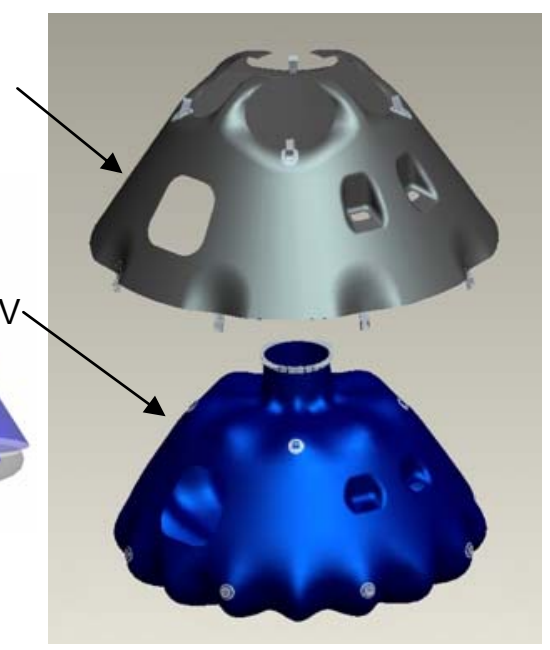

(c)

Figure 2.-Design concepts considered for the composite CM: (a) Stiffened sandwich, (b) Monocoque, (c) Geometrically stiffened.

HyperSizer utilizes panel and beam loads from the FEA model to evaluate a wide array of panel and beam concepts and geometries with respect to numerous composite strength and stability failure criteria. Each panel and beam component (which may be composed of several elements) is sized based on its local, statistically processed loads to determine the lightest panel/beam design that produces positive margins for all applicable failure criteria. The optimum designs are chosen from a group of (typically several thousand) candidate designs specified by the user through material/layup choices and geometric variable (e.g., honeycomb core thickness) ranges and permutations. The lightest workable panel and beam concepts as determined by HyperSizer are then automatically included within a new finite element model to be re-evaluated by NASTRAN. New loads are then obtained from the NASTRAN output, enabling updated optimized designs of the panels and beams to be determined by HyperSizer. This process is iterated until convergence of the overall design has been achieved, as indicated by a (nearly) stable weight and design. A new software product, called HyperFEA (ref. 5) now automates this iterative process between the HyperSizer and NASTRAN software packages, streamlining the preliminary design process considerably.

In addition to the IM7/977-2 graphite/epoxy composite (considered to be the baseline composite material for the NESC composite CM project), discontinuously reinforced aluminum (DRA) (ref. 6) and WebCore (refs. 7 and 8) materials were considered. DRA is an aluminum matrix composite with silicon carbide inclusions that can be cast, rolled, or extruded. WebCore is a sandwich panel core material consisting of a fiber reinforced foam, with or without open regions and integral polymer matrix composite 
webs. DRA has been considered for panel facesheets and beams in the stiffened sandwich CM concept, while WebCore has been considered as a sandwich panel core material across all three CM concepts. Section II of the paper defines the sizing analysis parameters, and also provides a single panel sizing study comparing WebCore with traditional metallic honeycomb sandwich panels. Sections III to V discuss the sizing analyses performed for each of the three composite CM concepts.

\section{Problem Definition}

The preliminary design sizing studies performed focus on the CM pressure vessel (PV), which is the actual crew cabin that maintains positive pressure throughout the mission. As shown in figure 2(b), the pressure vessel is encased by an aeroshell and heat shield, which protect the PV and support the thermal protection system materials. Analyses performed on the stiffened sandwich concept consider only the PV, while the aeroshell and heat shield are assumed to be the legacy designs from the Smart Buyer Team project. In the case of the monocoque concept, the aeroshell is partially integrated with the PV, so both the PV and the aeroshell have been sized, while the legacy heat shield design is assumed. Finally, for the geometrically stiffened concept, while the unique aeroshell (fig. 2(c)) has undergone conceptual design, only the PV has been sized.

\section{A. Applied Loading}

The load cases considered for the CM are shown in figure 3 and summarized in table 1. Highlighted in figure 3 are the $15 \mathrm{~g}$ LAS pull-off load that would be used for escape were there an unintended event associated with the rocket stack during launch. The late abort case is also extreme,

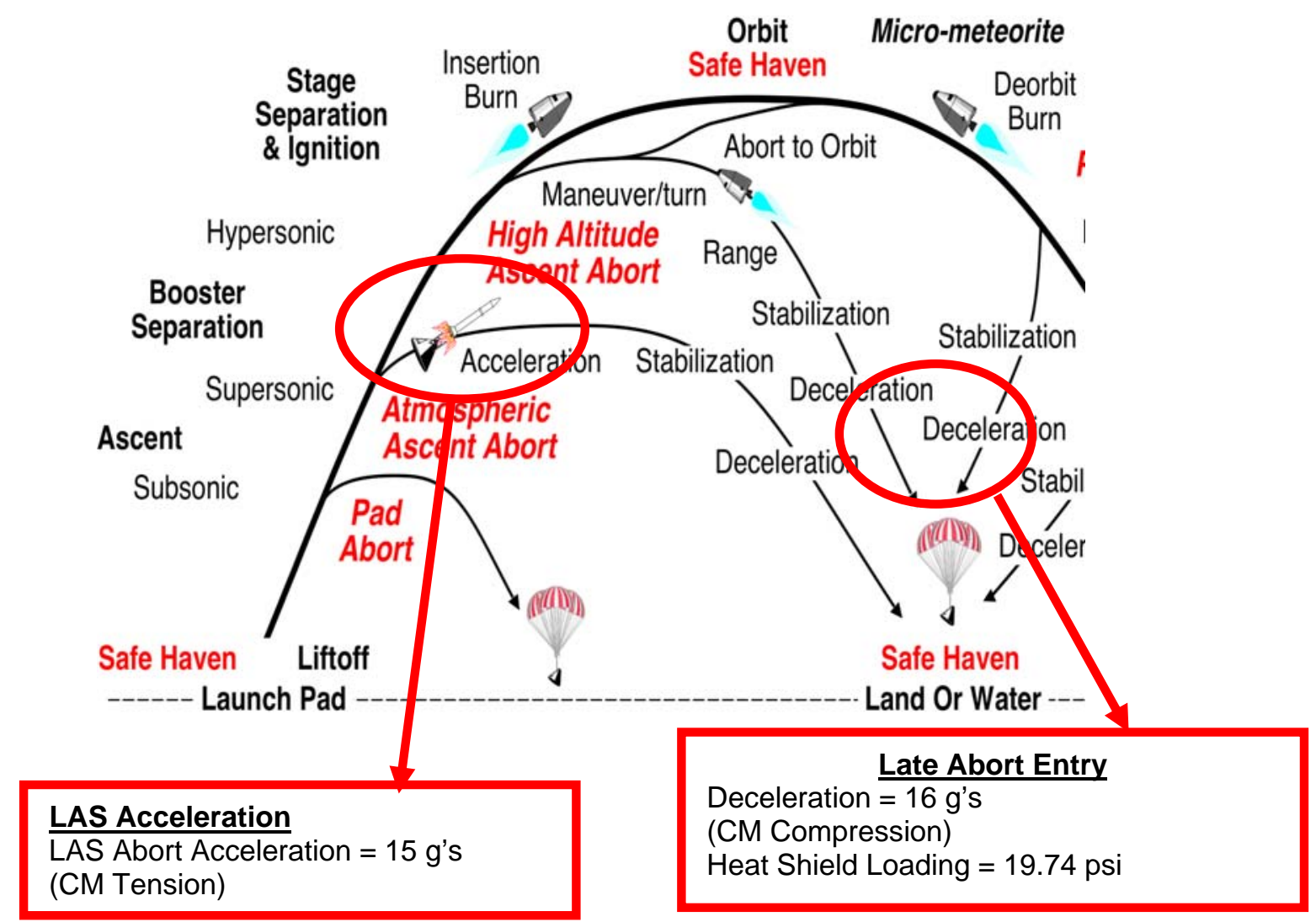

Figure 3.-Schematic showing a variety of potential loading scenarios for the CM. 
imposing a $16 \mathrm{~g}$ deceleration on the CM. In addition, as described in table 1, the internal pressure load case and standard second stage launch $5 \mathrm{~g}$ load case are considered, along with combinations of the internal pressure with the other load cases. The load cases considered for each CM concept, along with the associated load and buckling factors employed in the sizing analyses, are shown in table 2 . The limit and ultimate factors are standard factors of safety that multiply the loads to which the CM had been sized, while the buckling factor is a knockdown used to account for correlation between test results and standard analytical methods employed for curved panel buckling. A dash in table 2 indicates that the load case was not considered for the sizing of that concept. Note that the narrowing of the load cases considered for the monocoque and geometrically stiffened CM concepts compared to the stiffened sandwich CM concept was motivated by programmatic considerations.

TABLE 1.-CM PV LOAD CASES CONSIDERED

\begin{tabular}{|c|c|c|c|}
\hline Load case & Acceleration & $\begin{array}{c}\text { Mass, } \\
\text { (lb) }\end{array}$ & Internal forces \\
\hline 1) Internal pressure (15 psi) & NA & NA & $\begin{array}{l}\text { Bi-axial tension } \\
\text { (hoop dominate) }\end{array}$ \\
\hline $\begin{array}{l}\text { 2) } 15 \text { g LAS Pad Abort } \\
\text { distributed attachment }\end{array}$ & $\begin{array}{l}15 \mathrm{~g} \\
\text { Applied at top of CM }\end{array}$ & $17,000 \mathrm{CM}$ & Tension in walls \\
\hline 3) 5 g 2nd stage ascent & $\begin{array}{l}5 \mathrm{~g} \\
\text { Applied at bottom of CM at } \\
\text { eight points }\end{array}$ & 30,000 CM and LAS & Compression in walls \\
\hline 4) 16 g Late Abort Decent & $\begin{array}{l}19 \mathrm{psi} \\
\text { Applied as pressure }\end{array}$ & $17,000 \mathrm{CM}$ & $\begin{array}{l}\text { Compression in walls, } \\
\text { bending in floor }\end{array}$ \\
\hline $\begin{array}{c}5 \text { to } 7 \text { ) Cases } 2 \text { to } 4 \text { combined } \\
\text { with pressure case } 1\end{array}$ & ----------------------- & ----------------------- & |------------------------ \\
\hline
\end{tabular}

TABLE 2.-LOAD FACTORS EMPLOYED FOR EACH CONCEPT AND LOAD CASE

\begin{tabular}{|c|c|c|c|c|c|c|c|c|c|}
\hline & \multicolumn{3}{|c|}{ Stiffened sandwich } & \multicolumn{3}{c|}{ Monocoque } & \multicolumn{3}{c|}{ Geometrically stiffened } \\
\hline $\begin{array}{c}\text { Load } \\
\text { case }\end{array}$ & Limit & Ultimate & Buckling & Limit & Ultimate & Buckling & Limit & Ultimate & Buckling \\
\hline 1 & 1.1 & 1.4 & 0.75 & 2.0 & 2.0 & 0.75 & 2.0 & 2.0 & 0.75 \\
\hline 2 & 1.1 & 1.4 & 0.75 & 1.1 & 1.4 & 0.75 & 1.4 & 1.4 & 0.75 \\
\hline 3 & 1.1 & 1.4 & 0.75 & - & - & - & - & - & - \\
\hline 4 & 1.1 & 1.4 & 0.75 & 1.1 & 1.4 & 0.75 & 1.4 & 1.4 & 0.75 \\
\hline 5 & 1.1 & 1.4 & 0.75 & - & - & - & - & - & - \\
\hline 6 & 1.1 & 1.4 & 0.75 & - & - & - & - & - & - \\
\hline 7 & 1.1 & 1.4 & 0.75 & - & - & - & - & - & - \\
\hline
\end{tabular}

The deformations resulting from load cases 1 and 2 are shown in figure 4, while those associated with load cases 3 and 4 are shown in figure 5. These results are plotted for the stiffened sandwich CM concept.

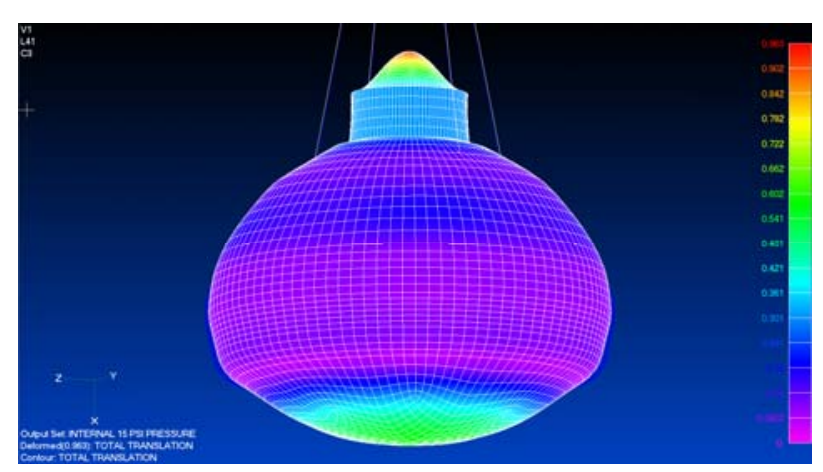

Load Case 1: 15 psi internal pressure.

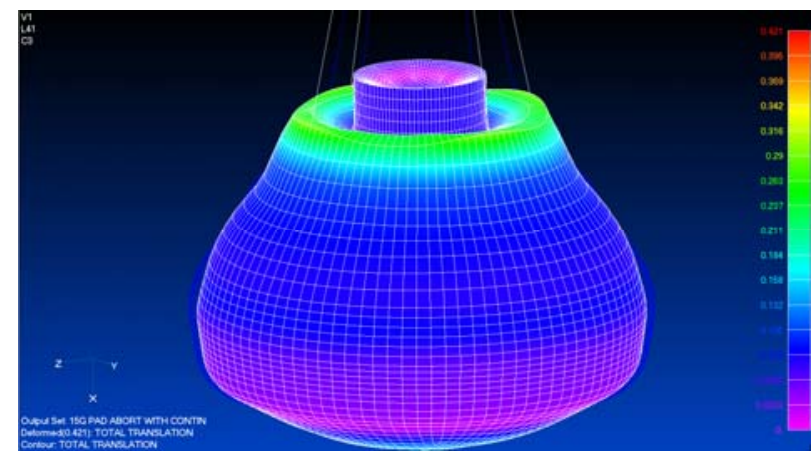

Load Case 2: $15 \mathrm{~g}$ vertical acceleration with continuous LAS attachments.

Figure 4.- The resulting PV displacement profile for the stiffened sandwich concept is shown given the applied load case. Plotted displacements are amplified by a factor of 50 . 

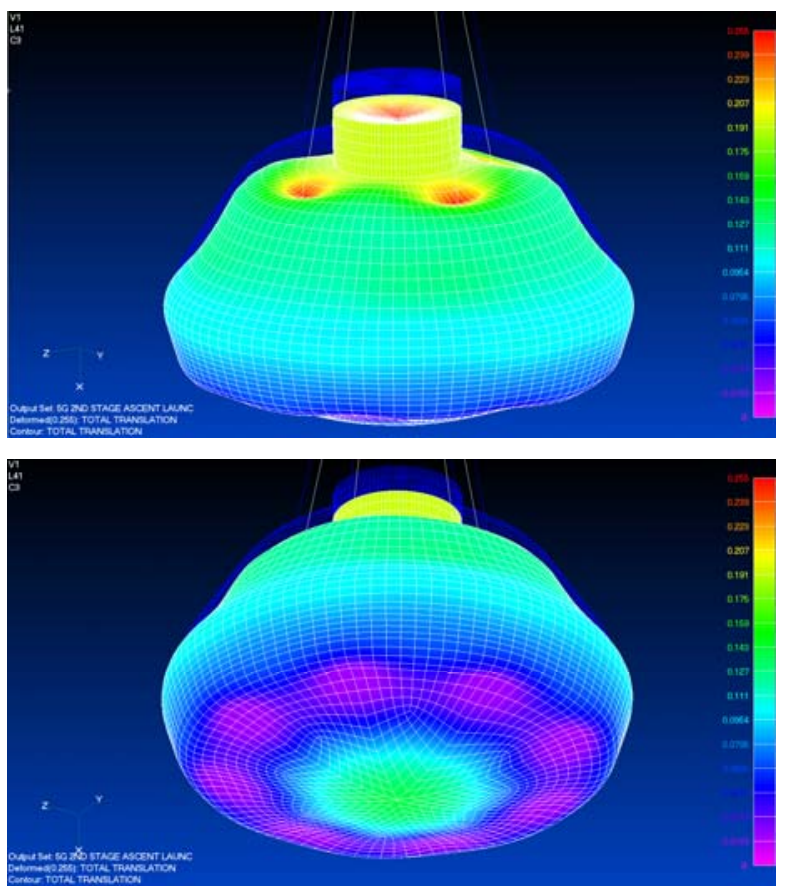

Load Case 3: $5 \mathrm{~g}$ vertical acceleration during 2nd stage ascent.
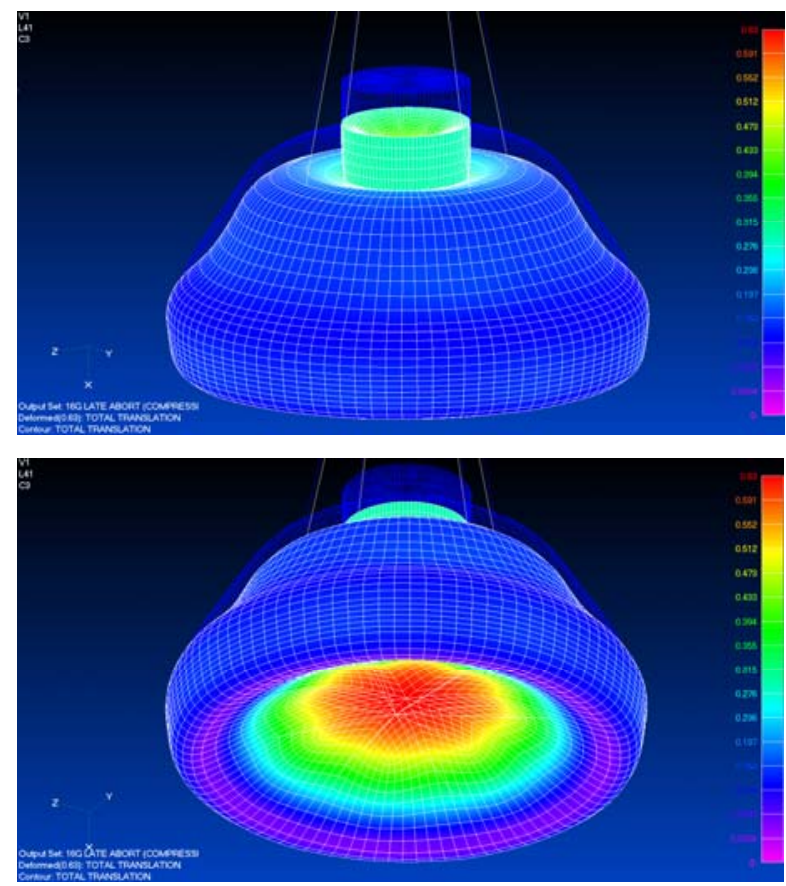

Load Case 4: $16 \mathrm{~g}$ late abort acceleration applied as an external pressure.

Figure 5.-The resulting PV displacement profile is shown for the stiffened sandwich concept given the applied load case. Plotted displacements are amplified by a factor of 50 .

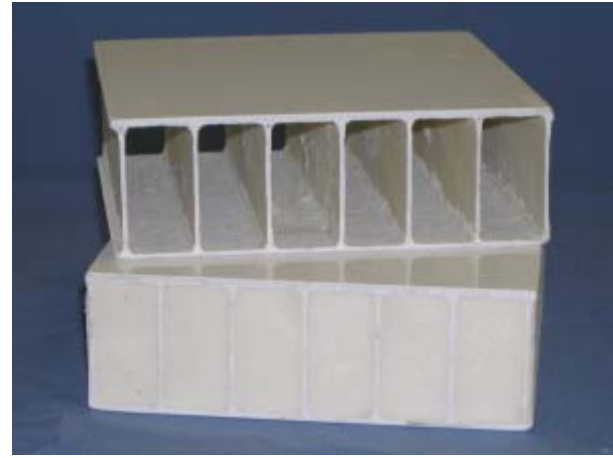

(a)

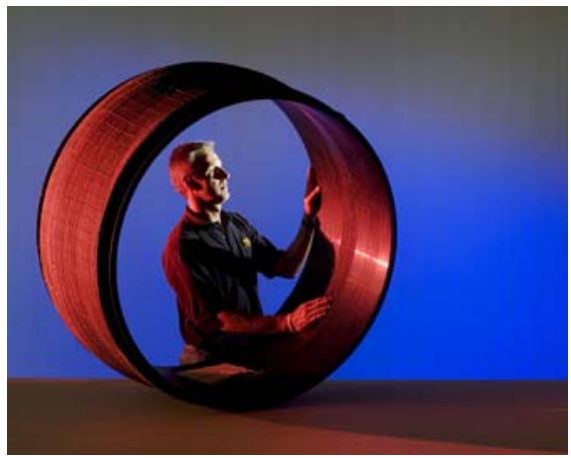

(b)

Figure 6.-(a) WebCore panels with and without foam removed. (b) Engine casing with double curvature manufactured with WebCore.

\section{B. Materials}

The material trade space considered included four types of sandwich panel cores: aluminum honeycomb, titanium honeycomb, TEEK foam, and WebCore integrally stiffened core (ref. 7). Facesheet and solid shell materials considered were Al-Li, discontinuously reinforced aluminum (DRA), Ti-6-4, and the graphite/epoxy composite IM7/977-2. Beam materials considered were DRA, aluminum 2219, and IM7/977-2. WebCore panels are formed by winding fibers around foam beams, stacking the wound beams, and winding fibers around the stack, followed by resin infusion. The result, as shown in figure 6 , is a panel with facesheets and integral webs. The foam can be removed after the resin has been infused and cured. TEEK is a closed-cell foam designed and patented at NASA Langley Research Center (ref. 9). WebCore and TEEK core properties (with no facesheets) are compared with other core materials in table 3. Sample facesheet and beam material properties are given in table 4 . 
TABLE 3.-SAMPLE CORE MATERIAL PROPERTIES (SEE FIG. 7)

\begin{tabular}{|c|c|c|c|c|c|c|c|c|c|}
\hline & $\begin{array}{l}\text { Density, } \\
\text { (pcf) }\end{array}$ & $\begin{array}{l}\text { Et, } \\
(\mathrm{ksi})\end{array}$ & $\begin{array}{l}\text { Ec, } \\
(\mathrm{ksi})\end{array}$ & $\begin{array}{l}\mathrm{Gw} \\
(\mathrm{ksi})\end{array}$ & $\begin{array}{l}\mathrm{Gl}, \\
(\mathrm{ksi})\end{array}$ & $\begin{array}{l}\text { Ftu, } \\
\text { (psi) }\end{array}$ & $\begin{array}{l}\text { Fsuw, } \\
\text { (psi) }\end{array}$ & $\begin{array}{l}\text { Fsul, } \\
\text { (psi) }\end{array}$ & $\begin{array}{l}\text { Fcus, } \\
\text { (psi) }\end{array}$ \\
\hline WebCore A & 4.1 & 26.1 & 26.1 & 1.88 & 44.7 & 272 & 89 & 234 & 352 \\
\hline WebCore B & 7.3 & 128 & 128 & 10 & 161 & 595 & 89 & 1266 & 595 \\
\hline WebCore Light Bi & 7.5 & 68.0 & 68.0 & 9 & 35 & 1641 & 145 & 473 & 1641 \\
\hline WebCore TYCOR G6 Bi & 6.8 & 50 & 50 & 10 & 14 & 140 & 180 & 180 & 70 \\
\hline WebCore Dense $\mathrm{Bi}^{*}$ & 17.9 & 50 & 50 & 26.3 & 37 & 140 & 473 & 473 & 70 \\
\hline TEEK & 0.5 & 0.0494 & 0.0494 & 0.019 & 0.019 & 22.6 & 8.7 & 8.7 & 22.6 \\
\hline TEEK & 2 & 0.322 & 0.322 & 0.124 & 0.124 & 76.8 & 29.6 & 29.6 & 76.8 \\
\hline TEEK & 5 & 1.6 & 1.6 & 0.616 & 0.616 & 330 & 127 & 127 & 330 \\
\hline TEEK & 8 & 1.96 & 1.96 & 0.752 & 0.752 & 431 & 166 & 166 & 431 \\
\hline TEEK filled $\mathrm{Al} \mathrm{HC}$ & 4.8 & 35 & 35 & 4 & 4 & 128 & 111 & 111 & 238 \\
\hline $\begin{array}{l}\text { Hexcel 3/8-5052-0.0020 } \\
\text { Al HC }\end{array}$ & 3.1 & 70 & 70 & 21 & 43 & 200 & 85 & 145 & 200 \\
\hline $\begin{array}{l}\text { Hexcel 1/8-5052-0.0007 } \\
\text { Al HC }\end{array}$ & 3.1 & 75 & 75 & 22 & 45 & 215 & 90 & 155 & 215 \\
\hline $\begin{array}{l}\text { Hexcel 1/8-5052-0.0010 } \\
\text { Al HC }\end{array}$ & 4.5 & 150 & 150 & 31 & 70 & 405 & 168 & 285 & 405 \\
\hline $\begin{array}{l}\text { Hexcel 1/8-5052-0.0015 } \\
\text { Al HC }\end{array}$ & 6.1 & 240 & 240 & 41 & 98 & 680 & 272 & 455 & 680 \\
\hline $\begin{array}{l}\text { Ti-3Al-2.5V-0.002-3/8 Ti } \\
\text { HC }\end{array}$ & 3.3 & 61.3 & 61.3 & 10.9 & 15.6 & 559 & 147 & 183 & 260 \\
\hline $\begin{array}{l}\text { Ti-3Al-2.5V-0.002-1/4 Ti } \\
\text { HC }\end{array}$ & 4.9 & 107 & 107 & 20.2 & 28.8 & 917 & 250 & 313 & 465 \\
\hline $\begin{array}{l}\text { Ti-3Al-2.5V-0.002-3/16 } \\
\text { Ti HC }\end{array}$ & 6.5 & 160 & 160 & 31.1 & 44.4 & 1300 & 365 & 456 & 702 \\
\hline $\begin{array}{l}\text { Ti-3Al-2.5V-0.002-1/8 Ti } \\
\text { HC }\end{array}$ & 9.8 & 286 & 286 & 58.5 & 83.5 & 2172 & 632 & 790 & 1280 \\
\hline
\end{tabular}

*Assumed properties determined via extrapolation (ref. 10).
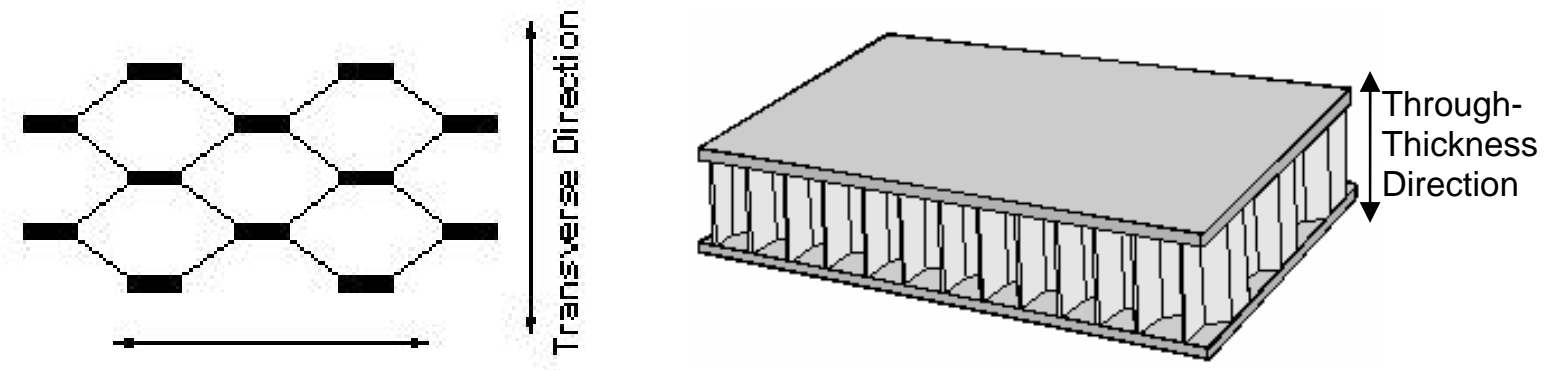

Ribbon Direction (aka longitudinal)

Ribbon (I) and Transverse (w) Direction Properties:

$\mathrm{Gl}=$ ribbon shear modulus

$\mathrm{Gw}=$ transverse shear modulus

Fsul = ribbon direction TT shear stress allowable

Fsuw $=$ transverse direction TT shear stress allowable
Through-Thickness (TT) Direction Properties:

$\mathrm{Et}=$ tensile $\mathrm{TT}$ modulus

$\mathrm{Ec}=$ compressive TT modulus

$\mathrm{Ftu}=$ tensile TT stress allowable

Fcus $=$ stabilized compressive TT stress allowable

Figure 7.-Definitions for core material properties given in table 3 . 
TABLE 4.-SAMPLE FACESHEET AND BEAM MATERIAL PROPERTIES

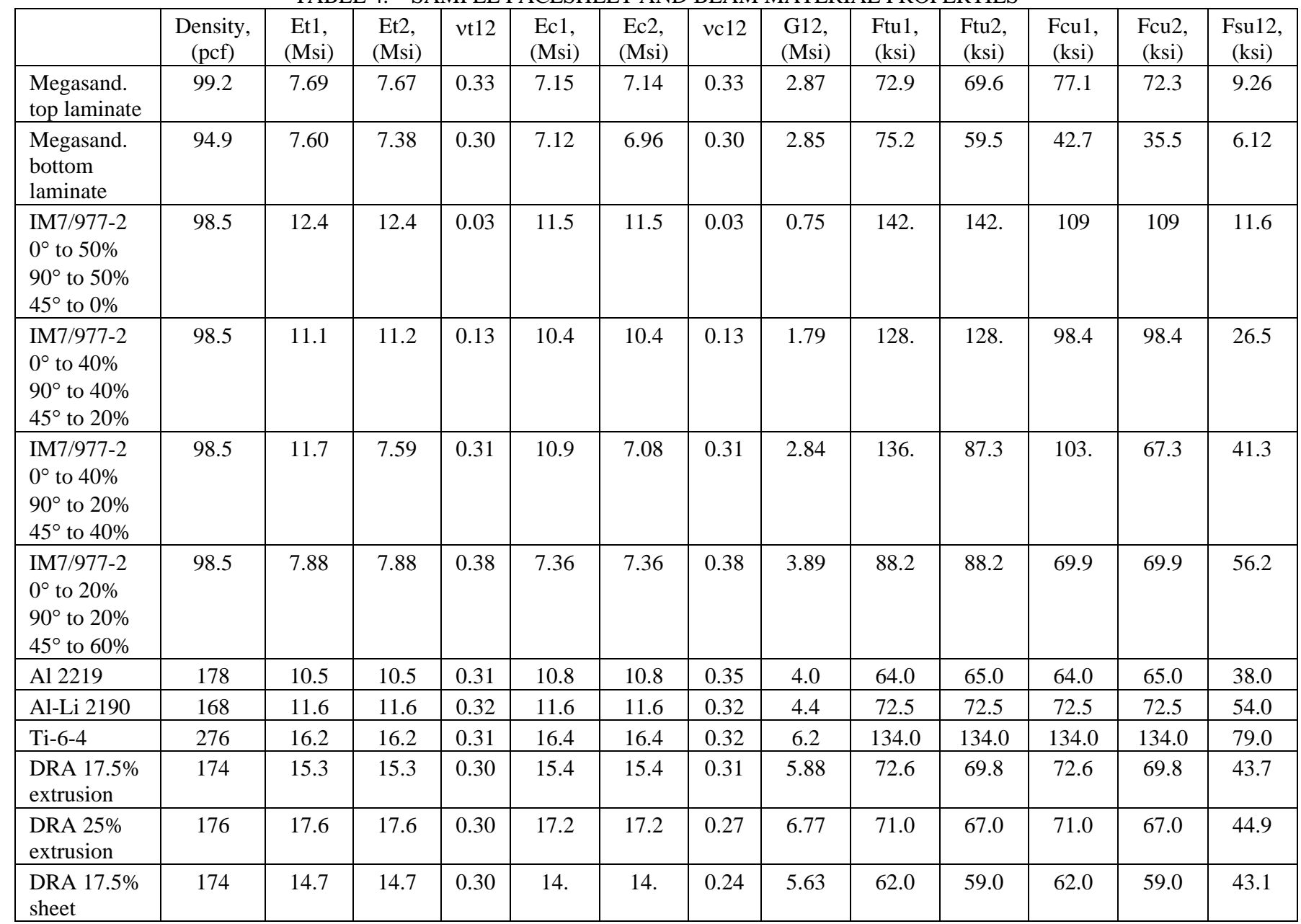

Et1 $=0^{\circ}$ tensile Young's modulus; Et2 $=90^{\circ}$ tensile Young's modulus; vt12 $=$ in-plane tensile Poisson ratio; Ec1 $=0^{\circ}$ compressive Young's modulus; Ec2 $=90^{\circ}$ compressive Young's modulus; vc12 = in-plane compressive Poisson ratio; G12 = in-plane shear modulus; Ftu1 $=0^{\circ}$ ultimate tensile stress allowable; Ftu2 $=90^{\circ}$ ultimate tensile stress allowable; Fcu1 $=0^{\circ}$ ultimate compressive stress allowable; Fcu2 $=90^{\circ}$ ultimate compressive stress allowable; Fsu12 = ultimate in-plane shear stress allowable.

\section{Single Panel Sizing}

We begin by performing a panel level study comparing WebCore sandwich panels to Al honeycomb panels in order to illustrate the benefits of the WebCore material under certain types of loading. The load cases considered in this panel level study are shown in table 5. Note, for Load Case (LC) 1, the WebCore material was treated as an orthotropic material rather than a honeycomb material in HyperSizer to account for its in-plane contribution. Honeycomb materials are treated as if they provide no in-plane contribution in HyperSizer. For LCs 2 to 4, the WebCore was treated as a honeycomb material in HyperSizer to account properly for its transverse shear contribution. Only WebCore A, B, and Light Bi were employed in this trade study, whereas all four Hexcel aluminum honeycomb materials shown in table 3 were included. A knockdown factor of 0.85 on strength was employed for core thicknesses greater than $1.5 \mathrm{in}$. for both the aluminum honeycomb and the WebCore material. An isotropic facesheet material (properties of Ti-6-4, see table 4) was used to complete the panel for both the WebCore and the honeycomb panels. 
TABLE 5.-PANEL LEVEL TRADE STUDY LOAD CASES

\begin{tabular}{|l|l|l|}
\hline Load case & \multicolumn{1}{|c|}{ Description } & \multicolumn{1}{|c|}{ Panel loads } \\
\hline 1 & Uniaxial compression & -Nx \\
\hline 2 & Pressure on 30 by 30 in. flat panel with fixed BCs & Qx, Qy, Mx, My \\
\hline 3 & Pressure on 30 by 150 in. flat panel with fixed BCs & Qx, Mx \\
\hline 4 & Uniaxial transverse shear & Qx or Qy \\
\hline
\end{tabular}

An isotropic facesheet was chosen to simplify the sizing process (the facesheet thickness was sized) and isolate the impact of the core material. Results were generated in the form of plots of load level vs. panel unit weight for the two types of panels in figures 8 and 9. Note that each data point in these plots represents a full panel sizing in which the specific type of WebCore or honeycomb was chosen, along with the thickness of the core and facesheet, in order to optimize the panel weight while successfully carrying the applied loads (with factors of safety identical to the stiffened sandwich concept, see table 2). HyperSizer considers an array of failure criteria that account for many failure modes that occur in sandwich panels including panel buckling, intracell dimpling, wrinkling, shear crimping, core crushing, and core shear failure, in addition to composite strength criteria (applicable to the facesheets) such as max. stress, max. strain, Tsai-Hill, Tsai-Wu, and LaRC03. The lightest panel design (of the options made available to the software by the user) that satisfies all failure criteria (i.e., providing all positive margins) is then reported as the optimum configuration. In the present panel study, in the case of honeycomb panels, $0.2 \mathrm{lb} / \mathrm{ft}^{2}$ have been added to the panel unit weights (represented as an additional curve in the plots) to account for adhesive between the facesheets and the core. Because WebCore panels are typically consolidated in one step, adhesive is typically not required.

Figure 8 shows results for LC 1 and 4, which are predominantly unidirectional load cases. In response to compressive uniaxial loading, we note that the response is dominated by facesheets. For the $\mathrm{Al}$ honeycomb panels, the core does not contribute to in-plane stiffness or strength, while for WebCore, the core in-plane stiffness and strength contribution is present, but appears to be minimal. For LC 1, WebCore is clearly competitive. Under uniaxial transverse shear, WebCore's main benefit (good transverse shear strength) is highlighted. The WebCore panel is far superior to the Al honeycomb panel for this unidirectional shear loading.

Figure 9 shows the results for panel level LC 2 and 3. For these types of loads, involving biaxial bending and biaxial shear load, HyperSizer checks the edge and midspan (pure moment) locations in the panel for failure. For load case 2, higher WebCore weights are observed because for WebCore A, B, and Light $\mathrm{Bi}$, while one direction has high transverse shear strength, the other direction has lower transverse shear strength compared to the Al honeycomb core (see table 3). Furthermore, WebCore is significantly affected by a facesheet wrinkling failure mode that may or may not be significant for this material concept. Over the applied load range, the honeycomb panel sizing switches to heavier, stronger material (thicker cell walls). The WebCore sizing is less able to do this because only three WebCore materials were considered, two of which have similar densities. It should be noted that the additional WebCore materials (Tycor G6 Bi and Dense Bi, see table 3) were subsequently added for consideration to address this issue. For load case 3, which involves more unidirectional bending and unidirectional shear loads (due to the longer panel dimension in one direction), WebCore is once again competitive. Again, the facesheet wrinkling failure mode has a major effect on the simulated WebCore performance. Figure 9 also includes plots for both WebCore and Al honeycomb in which the wrinkling failure mode has been disabled. This allows WebCore to become more competitive as this failure mode drives the WebCore panel design to a much greater extent than the $\mathrm{Al}$ honeycomb design. 

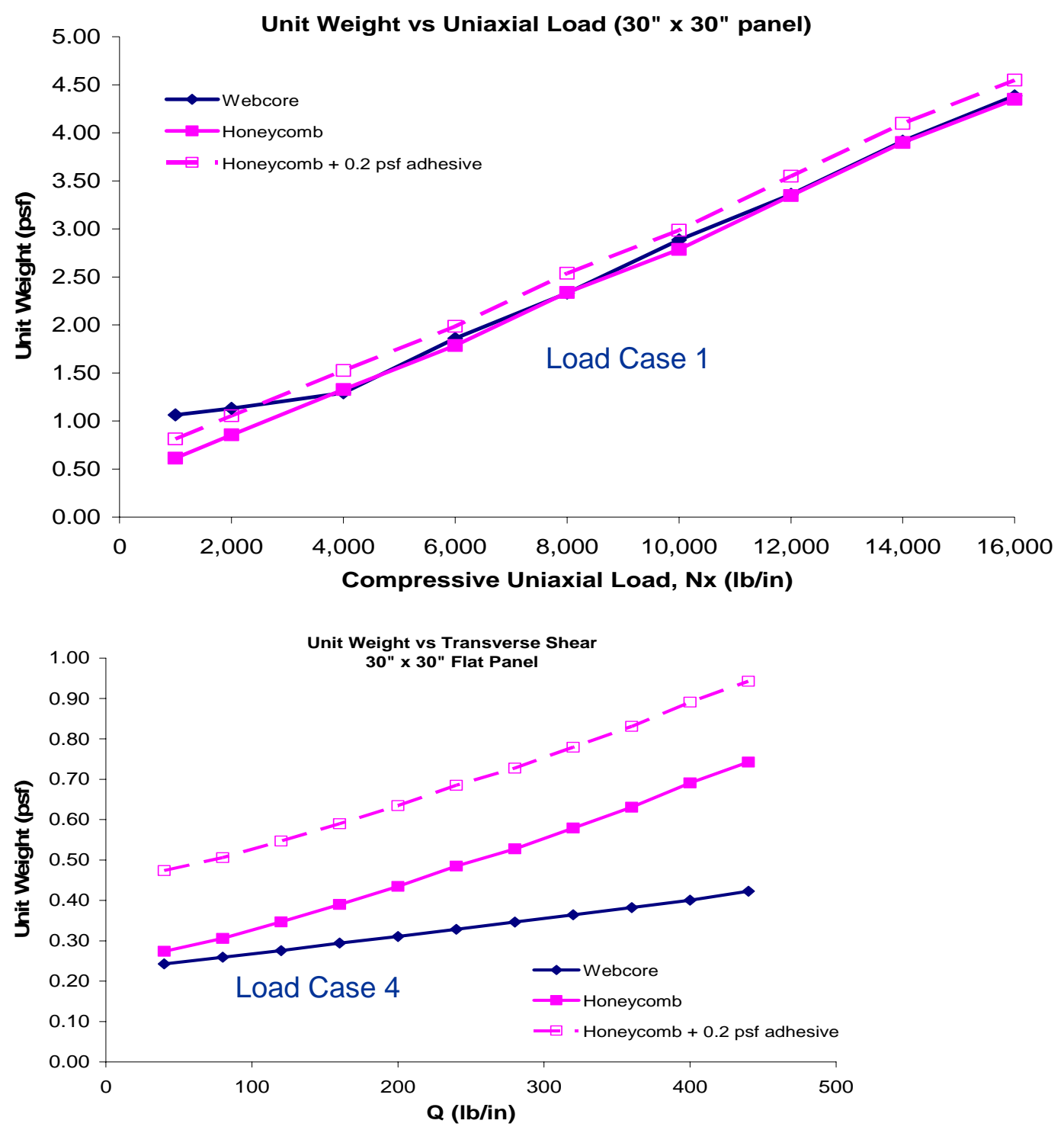

Figure 8.-Panel unit weights under uniaxial tension and pure transverse shear loading cases. 

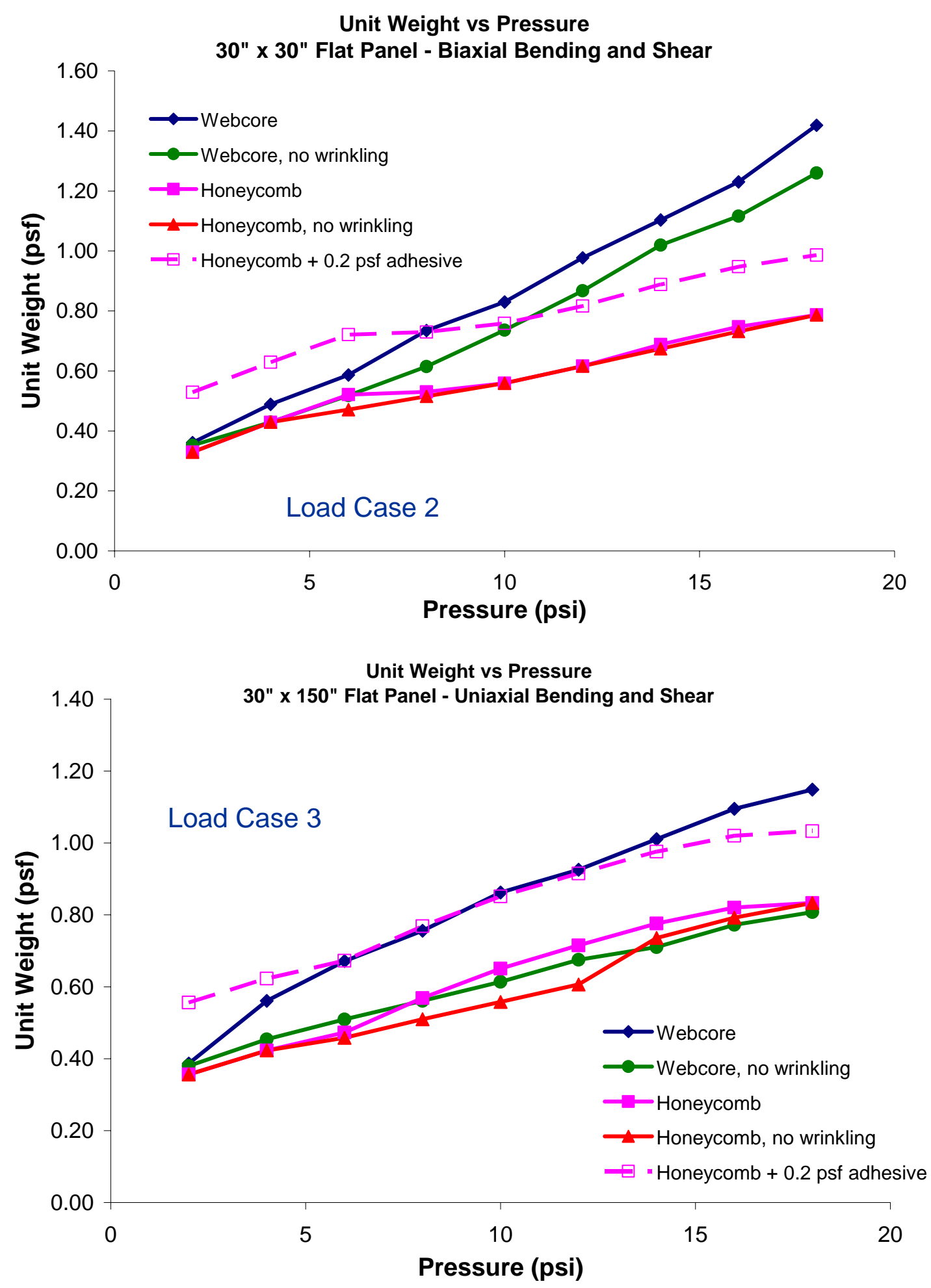

Figure 9._Panel unit weights under pressure loading on a square panel (biaxial) and a rectangular panel. 
From this panel level study, it has been observed that, for load cases that are nearly pure unidirectional transverse shear, the WebCore material is far superior to the Al honeycomb. WebCore is at least competitive under other load cases. It is important to consider the (probable) need for adhesive to bond the facesheets to Al honeycomb. This is likely not needed in WebCore as facesheets can be integrally manufactured. Given that WebCore properties can be tailored to specific applications, certain issues can be addressed, including better biaxial performance, improved facesheet wrinkling resistance (requires examination of this failure mode), and a positive linear relationship between performance and weight. In addition, the 0.85 strength knockdown for core thicknesses above $1.5 \mathrm{in}$. is likely not needed for WebCore, as results have shown that no such strength reduction occurs. Finally, it should be noted that pristine material properties have been used in this panel level study. Were knocked down properties used to account for the presence of damage, it is likely that WebCore's performance would have improved as WebCore has been shown to exhibit excellent damage tolerance. For these reasons, this single panel study should be considered as a worst case scenario for WebCore in its comparison with aluminum honeycomb.

\section{Stiffened Sandwich CM Concept}

We first consider the stiffened sandwich CM concept shown in figure 2(a). Recall that only the PV was sized for this concept, while the Smart Buyer Team aeroshell was assumed. Figure 10 shows the PV FEA model along with the material directions. Figure 11 shows the panel components that are sized independently within HyperSizer based on the panel loads determined from the NASTRAN FEA. Similarly, figure 12 shows the beam structural components that will be sized independently. Note that, of the WebCore materials listed in table 3, only WebCore A, B, and Light Bi were considered in the sizing of the stiffened sandwich CM concept.

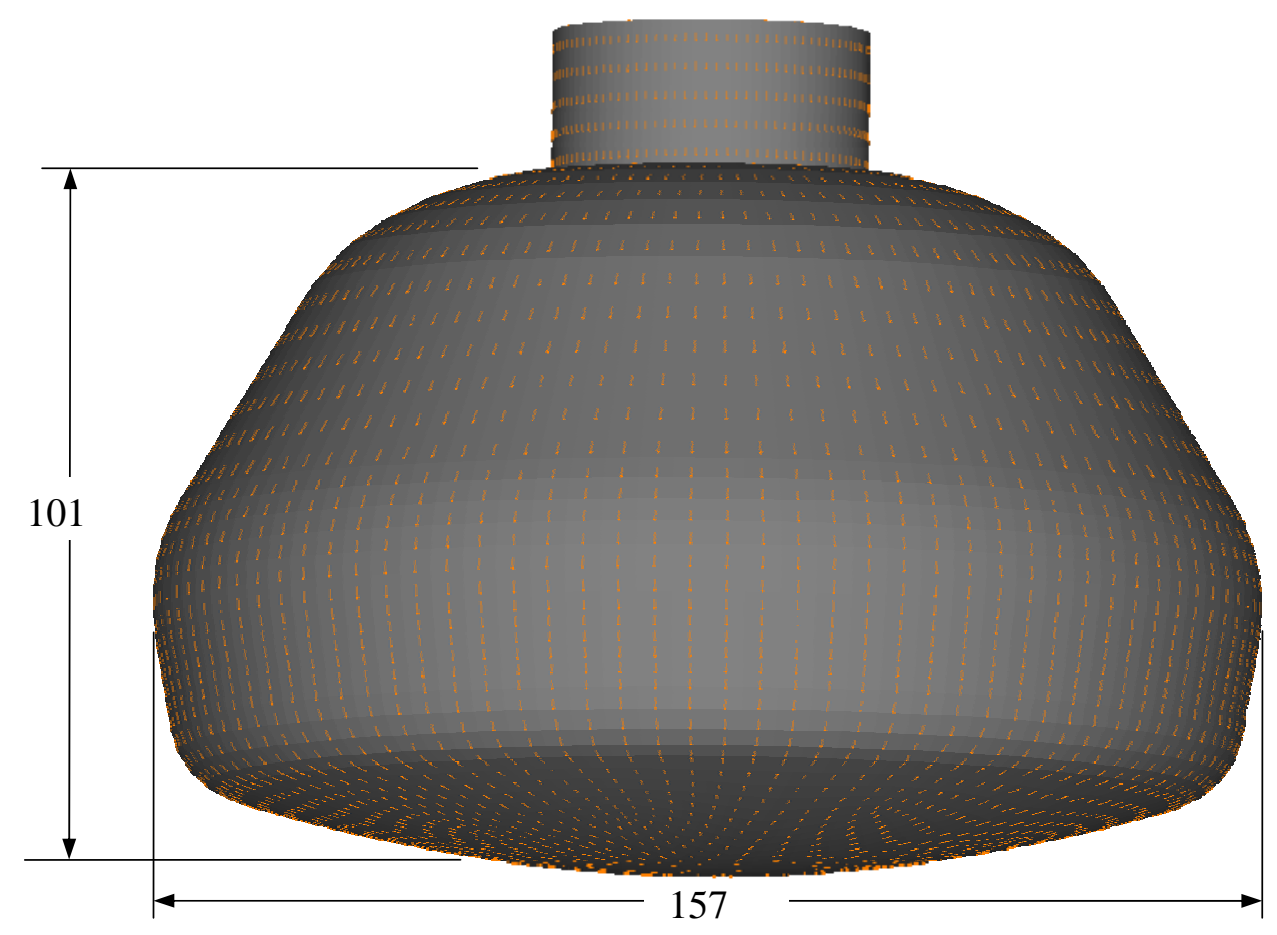

Figure 10.--Illustration of the geometry and FEA material direction of the pressure vessel for the stiffened sandwich CM concept. 


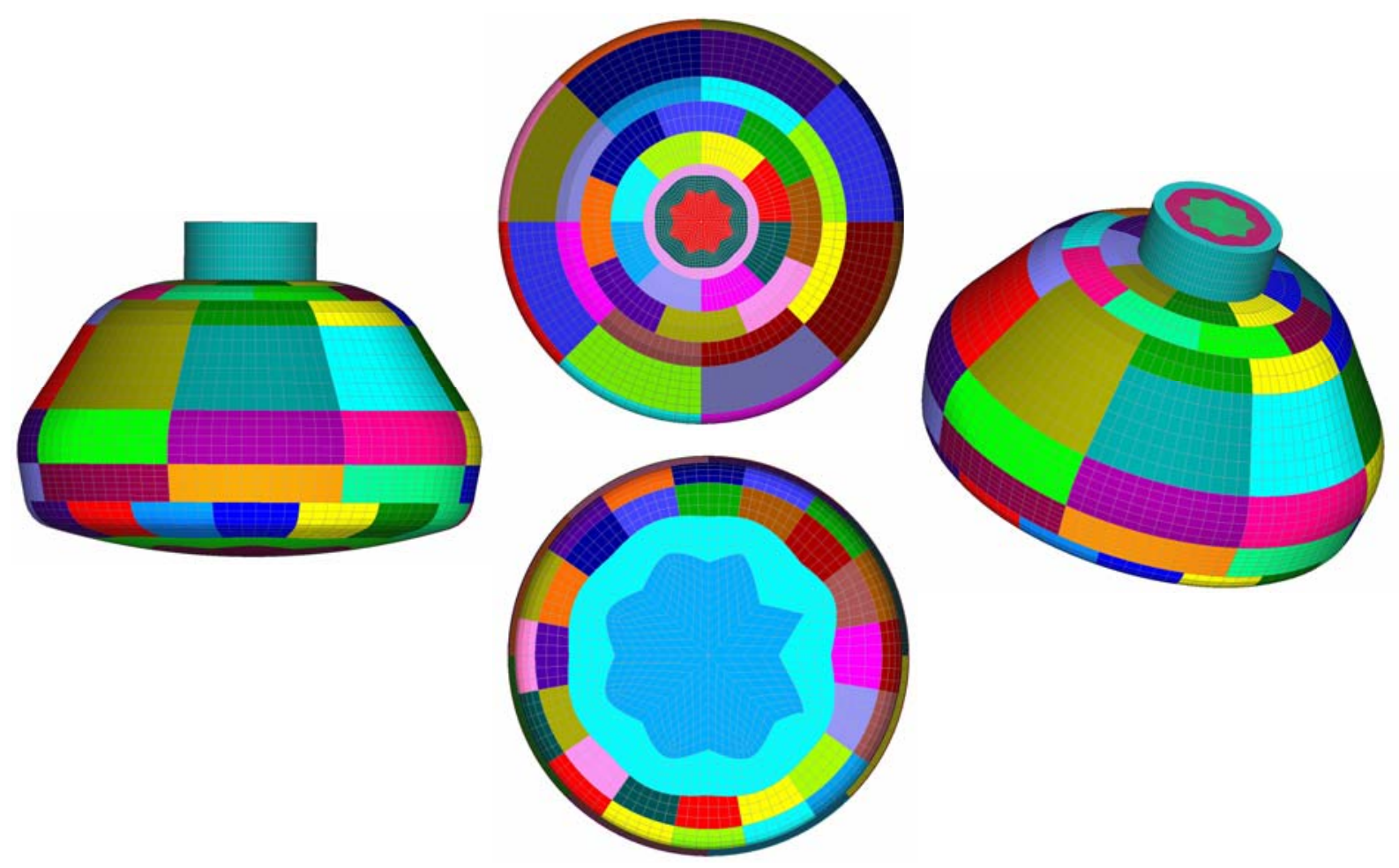

Figure 11.--Illustration of the finite element mesh and identified panel structural components that will each have constant properties during sizing within HyperSizer. Note that repeated colors do not indicate membership in the same component. Component membership is restricted to adjacent elements in the present application.

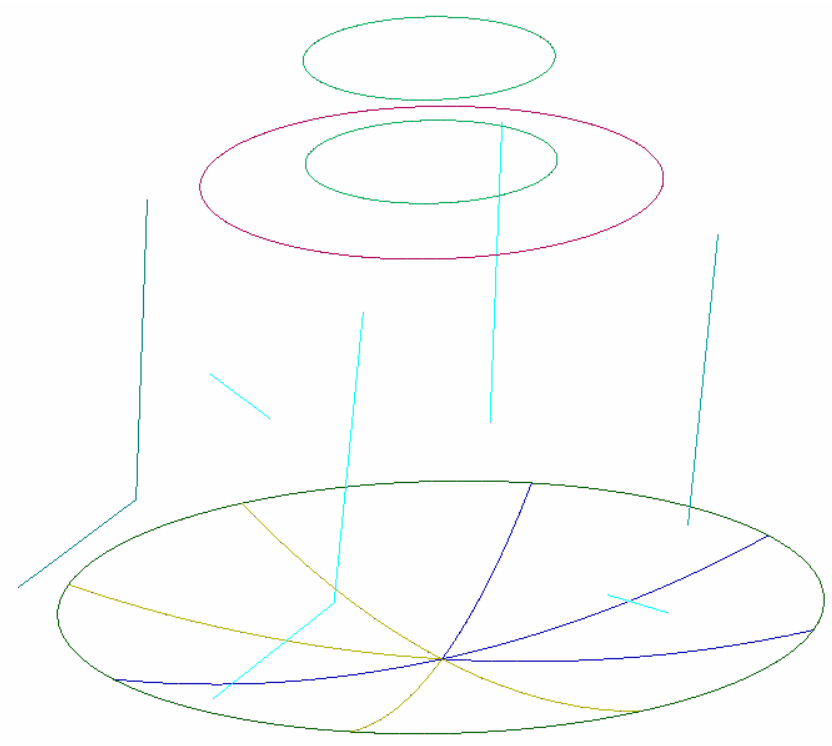

Beam \#50 "Component 50"

Beam \#51 "Component 51"

Beam \#52 "Component 52"

Beam \#53 "Component 53"

Beam \#60 "Component 60"

Beam \#4000021 "Component 4000021"

Figure 12.-Illustration of the beam structural components that will have constant properties during sizing within HyperSizer. 


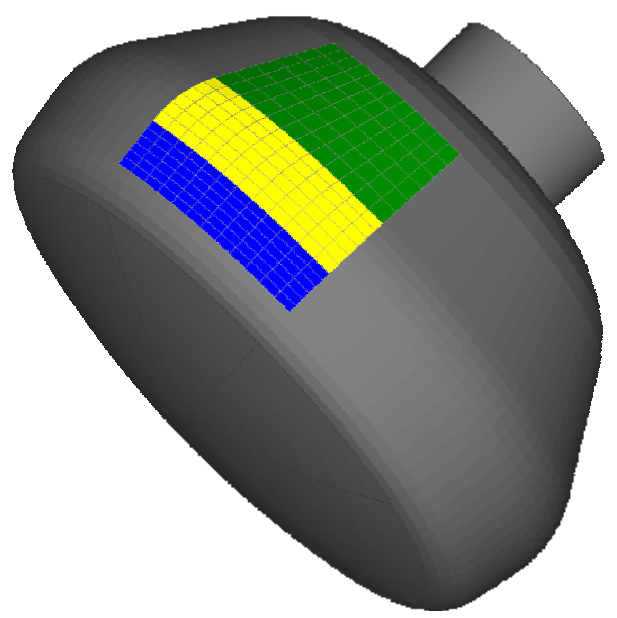

Figure 13.--Representative portion of the CM pressure vessel acreage.

\section{A. Representative Acreage}

The next step beyond the single panel sizing described in section II.C is the sizing a representative portion of the CM pressure vessel acreage using a variety of different materials. This representative portion consists of the three panels shown in figure 13. The loads on these panels are taken from a NASTRAN finite element model of the entire CM pressure vessel, which considered the seven load cases listed in table 1 . Note that the controlling load case for each panel is arbitrary. Thus, the three panels have been sized to realistic loads, but the iteration between HyperSizer and NASTRAN that is typically required in a full structural sizing is not performed in this study.

Results for this representative acreage study are given in table 6. In cases 1 to 4, which all involve aluminum honeycomb core panel designs, the graphite/epoxy (IM7/977-2) composite facesheet provides the lowest weight panel. Also, the DRA facesheet honeycomb panel is slightly lighter than the Al 2219 facesheet honeycomb panel. Case 5, which involves a graphite/epoxy composite facesheet with a WebCore core, is significantly lighter than the best Al honeycomb panel design (0.73 vs. 0.88 psf). It is also noted that these panels have been sized using pristine, undamaged material allowables. As mentioned previously, because WebCore has outstanding damaged residual properties, it is likely that under such conditions WebCore would show an even greater advantage.

TABLE 6.-SIZING RESULTS FOR THE THREE PANEL REPRESENTATIVE ACREAGE DESIGN STUDY

\begin{tabular}{|l|l|l|l|c|c|}
\hline \multicolumn{1}{|c|}{ Case } & \multicolumn{1}{|c|}{ Concept } & \multicolumn{1}{|c|}{ Facesheet material } & \multicolumn{1}{c|}{$\begin{array}{c}\text { Core material } \\
\text { (psf) }\end{array}$} & $\begin{array}{c}\text { Unit weight, } \\
(\mathrm{psf})\end{array}$ \\
\hline 1 & Sandwich & Al 2219 & $\begin{array}{l}\text { Al 5052 } \\
\text { honeycomb }\end{array}$ & 0.2 & 1.42 \\
\hline 2 & Sandwich & Ti 6-4-2 & $\begin{array}{l}\text { Al 5052 } \\
\text { honeycomb }\end{array}$ & 0.2 & 1.88 \\
\hline 3 & Sandwich & IM7/977-2 & $\begin{array}{l}\text { Al 5052 } \\
\text { honeycomb }\end{array}$ & 0.2 & $\mathbf{0 . 8 8}$ \\
\hline 4 & Sandwich & $\begin{array}{l}\text { DRA 17.5 percent sheet } \\
0.03 \text { in. min gage }\end{array}$ & $\begin{array}{l}\text { Al 5052 } \\
\text { honeycomb }\end{array}$ & 0.2 & 1.41 \\
\hline 5 & Sandwich & IM7/977-2 & WebCore & 0.0 & $\mathbf{0 . 7 3}$ \\
\hline 6 & Hat stiffened & Al-Li 2090 & LiAl 2090 & 0.0 & 1.44 \\
\hline 7 & Hat stiffened & $\begin{array}{l}\text { DRA 17.5 percent sheet } \\
0.03 \text { in. min gage }\end{array}$ & $\begin{array}{l}\text { DRA 17.5 percent } \\
\text { extrusion }\end{array}$ & 0.0 & 1.34 \\
\hline
\end{tabular}




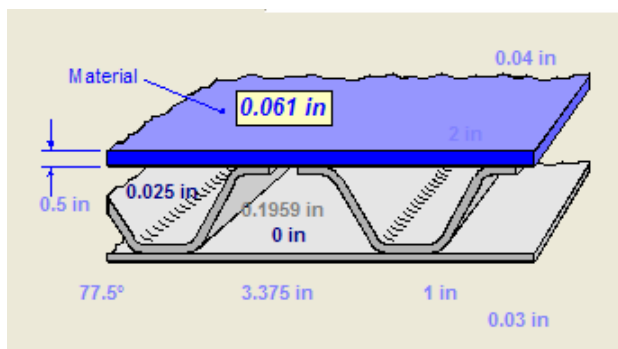

(a)

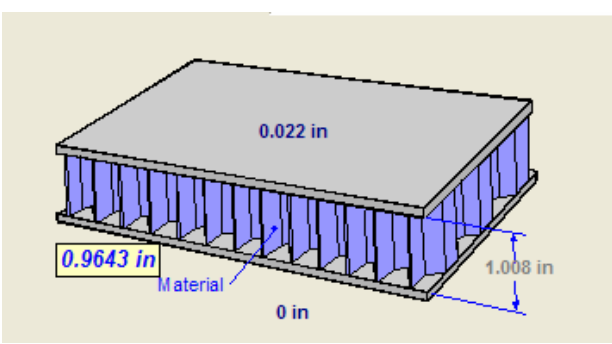

(b)

Figure 14.- Schematics showing the difference between the (a) hat stiffened panel concept and the (b) honeycomb sandwich panel.

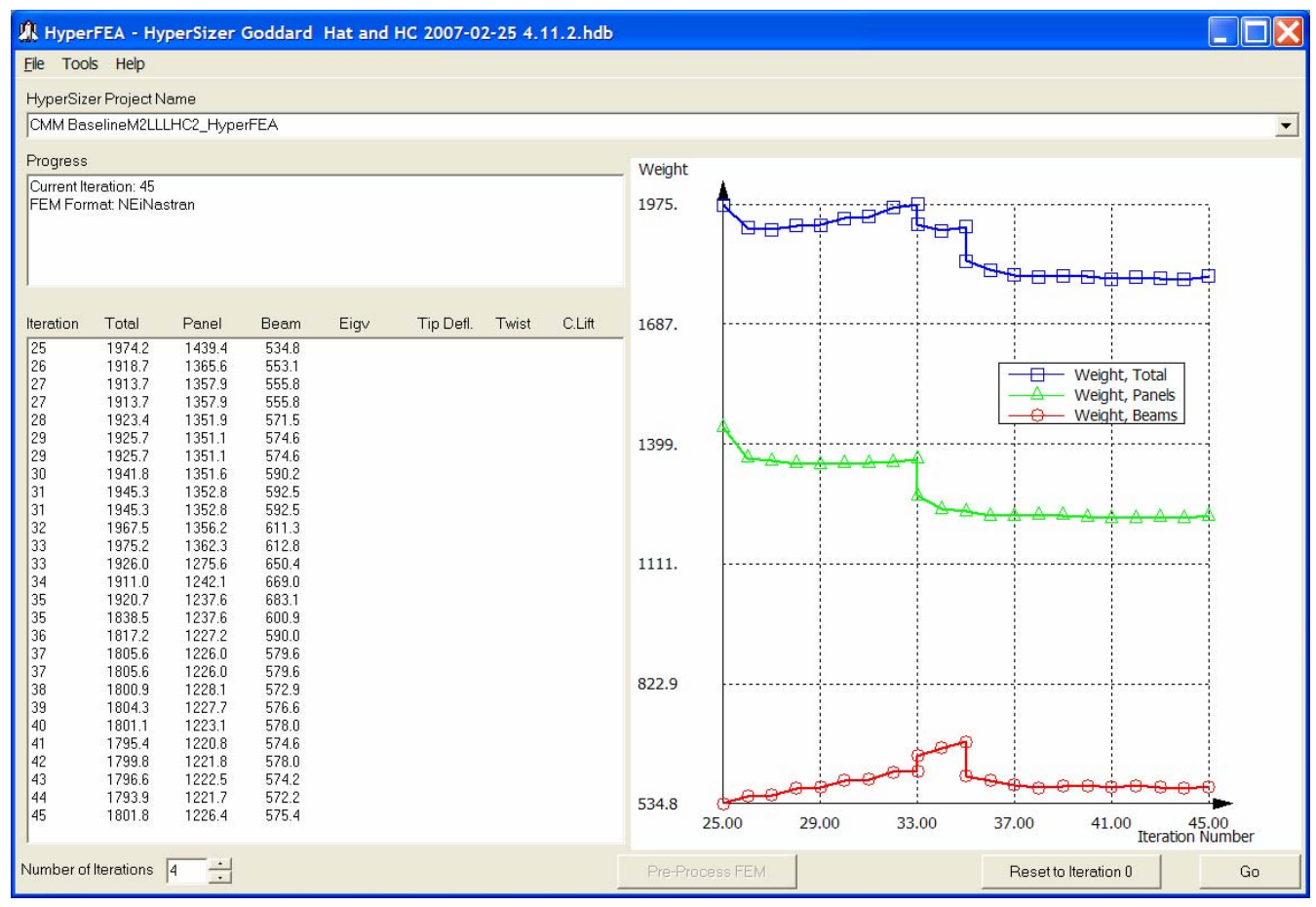

Figure 15.-In this HyperFEA interface, 21 iterations are shown between HyperSizer and NASTRAN FEA. Red = beam weight; Green = panel weight; Blue = total weight. Large discontinuous changes represent a change in HyperSizer data, such as adding/removing materials from consideration in the design.

Cases 6 and 7 compare the performance of two hat stiffened panel concepts; an Al-Li facesheet and stiffener panel and a DRA facesheet and stiffener panel (see fig. 14). It is observed that both of these concepts are competitive with the metallic sandwich panel concepts, with the DRA hat stiffened panel providing the lighter design. These studies show that, while IM7/977-2 provides the best weight efficiency, DRA can offer a weight advantage over aluminum alloys. Thus, if it is desirable to utilize a metallic-based design rather than a polymer matrix composite (e.g., for manufacturability, damage tolerance, or secondary attachment requirements), DRA may be an option that warrants consideration.

\section{B. Entire Pressure Vessel}

A sizing of the entire CM pressure vessel for the stiffened sandwich concept was performed through multiple iterations between HyperSizer and NASTRAN to achieve a converged design. These iterations were performed using the new HyperSizer HyperFEA tool (ref. 5), which automates the process of iterating between HyperSizer and NASTRAN. The HyperFEA interface is shown in figure 15, in which 

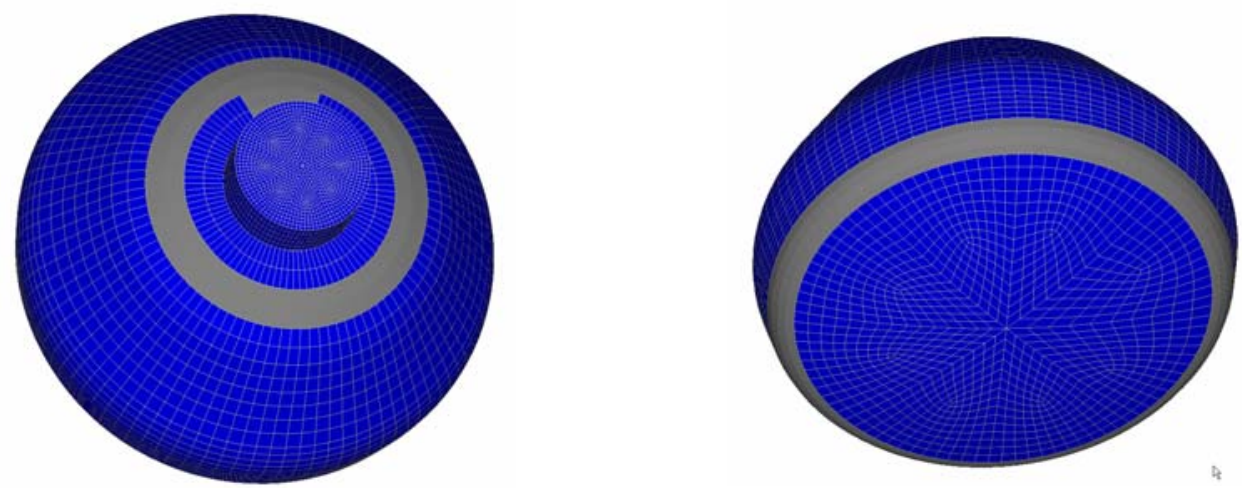

Figure 16.-The blue area of the stiffened sandwich concept CM illustrates the acreage that was included in the weight estimate of the vehicle. The gray area required different sandwich construction then that noted in table in order to support the significant out-of-plane forces in that region. Consequently, area was excluded from the weight calculation for consistency.

45 total iterations were performed (final 21 shown) in a considerably more efficient manner compared to standard operator-driven HyperSizer to NASTRAN iterations.

During the sizing procedure, it became clear that both the Al honeycomb and the WebCore A, B, and Light Bi materials could not support the loads with sufficient factors of safety in the gray regions indicated in figure 16 due to large geometry-induced out-of-plane loads. Thus, these regions were provided an identical heavier and stronger panel design in both the $\mathrm{Al}$ honeycomb and WebCore cases and excluded from the results presented herein. It was also shown that the WebCore Dense Bi core material was capable of supporting the loads in this region (not illustrated herein), but for consistency, the region was excluded from the weights reported in this study.

Panel results for the full CM pressure vessel sizing are given in table 7. Three sandwich panel cases were considered in the study; Al honeycomb core with DRA facesheets, Al honeycomb core with graphite/epoxy (IM7/977-2) facesheets, and WebCore core with graphite/epoxy (IM7/977-2) facesheets. The results show that the graphite/epoxy facesheets provide a significantly lower weight compared to DRA, when combined with the Al honeycomb core. The WebCore core provides a slightly lower weight when combined with the graphite/epoxy facesheets compared to the $\mathrm{Al}$ honeycomb core.

TABLE 7.-RESULTS FOR THE FULL STIFFENED SANDWICH CM CONCEPT PV SIZING [EXCLUDING GRAY REGIONS IN FIGURE 16]

\begin{tabular}{|c|c|c|c|c|}
\hline & & Panels & & \\
\hline Concept & Facesheet material & Core material & $\begin{array}{l}\text { Unit weight, } \\
\text { (psf) }\end{array}$ & $\begin{array}{c}\text { Total weight, } \\
\text { (lb) }\end{array}$ \\
\hline Sandwich & $\begin{array}{l}\text { DRA } 17.5 \text { percent } \\
\text { sheet }\end{array}$ & Al Honeycomb & 1.62 & 597 \\
\hline Sandwich & IM7/977-2 & Al Honeycomb & 1.07 & 394 \\
\hline Sandwich & IM7/977-2 & WebCore & 1.04 & 383 \\
\hline
\end{tabular}

In addition to the panels discussed above, the full stiffened sandwich CM concept PV finite element model contains a number of beams that are also sized with HyperSizer. The locations of these beams are shown in figure 12. For the case of graphite/epoxy facesheets and $\mathrm{Al}$ honeycomb core sandwich panels discussed above, the CM pressure vessel beams were sized using Al 2219 and DRA. Closed rectangular beams, as shown in figure 17, were considered in this preliminary design. Trades among different beam concepts (e.g., I-beams) were not performed. The results, summarized in table 8, show that the DRA beams are 16 percent lighter, representing a 24 lb weight savings. This again illustrates the potential benefit of DRA compared to a traditional metallic design. 


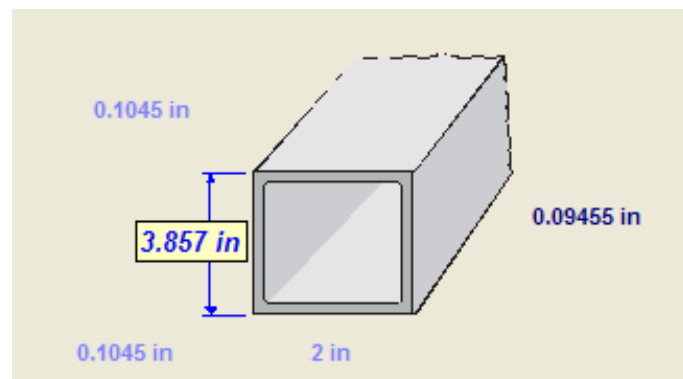

Figure 17.--Schematic showing a closed rectangular beam.

TABLE 8.-COMPARISON OF CM PRESSURE VESSEL BEAM WEIGHTS

\begin{tabular}{|c|c|c|}
\hline & Closed beams & \multicolumn{2}{c|}{$\begin{array}{c}\text { Total weight, } \\
(\mathrm{lb})\end{array}$} \\
\hline Material & $\begin{array}{c}\text { Unit weight, } \\
(\mathrm{lb} / \mathrm{ft})\end{array}$ & 171 \\
\hline Alum 2219 & 1.14 & 147 \\
\hline DRA Extrusion & 0.98 & 147 \\
\hline
\end{tabular}

\section{Monocoque CM Concept}

The monocoque concept for the CM arose out of the desire to explore combining the aeroshell and PV over a portion of the CM in order to take some advantage of the aeroshell structure to carry load. The FEA model for the monocoque CM was constructed by starting with the stiffened sandwich concept model and making appropriate alterations to combine the aeroshell and PV over a portion of the side wall. The four major alterations to the model are illustrated in figure 18. The side wall of the pressure vessel was moved outward to mate up with the aeroshell, which required alteration of the PV dome mold line and minor relocation of the LAS attachment ring. Finally, two additional ring frames were added in the lower shoulder region of the pressure vessel in order to accommodate the out-of-plane loads that were causing problems in the stiffened sandwich model, as shown in figure 16.

For the sizing of the monocoque CM concept, only load cases 1 , 2, and 4 were considered (see table 2). In addition, a factor of 2.0 was employed for the pressure load case. These differences from the stiffened sandwich concept analyses were motivated by programmatic decisions that occurred over the course of the NESC composite CM project.

A particular sandwich panel construction concept, called the "megasandwich," was originally associated with the monocoque CM concept. This sandwich panel, shown in figure 19, was designed with MMOD resistance in mind, and therefore include two separate glass cloth layers and three layers of Kevlar/Epoxy on the inner surface. This megasandwich panel concept was first evaluated for the monocoque CM concept in a study involving sizing the core utilizing all five TEEK cores listed in table 3 and utilizing the facesheet layup shown in figure 19. Note that the megasandwich top and bottom facesheet laminate effective properties are given in table 3. Next, full sizing studies were performed to optimize the design for the monocoque CM concept. In all cases, IM7/977-2 beams were sized, as were IM7/977-2 solid laminate feet (see fig. 18). It should also be noted that the portion of the aeroshell that is not part of the common region (see fig. 18), always sized to the minimum gauge configuration, and thus is not shown in the sizing plots below. 


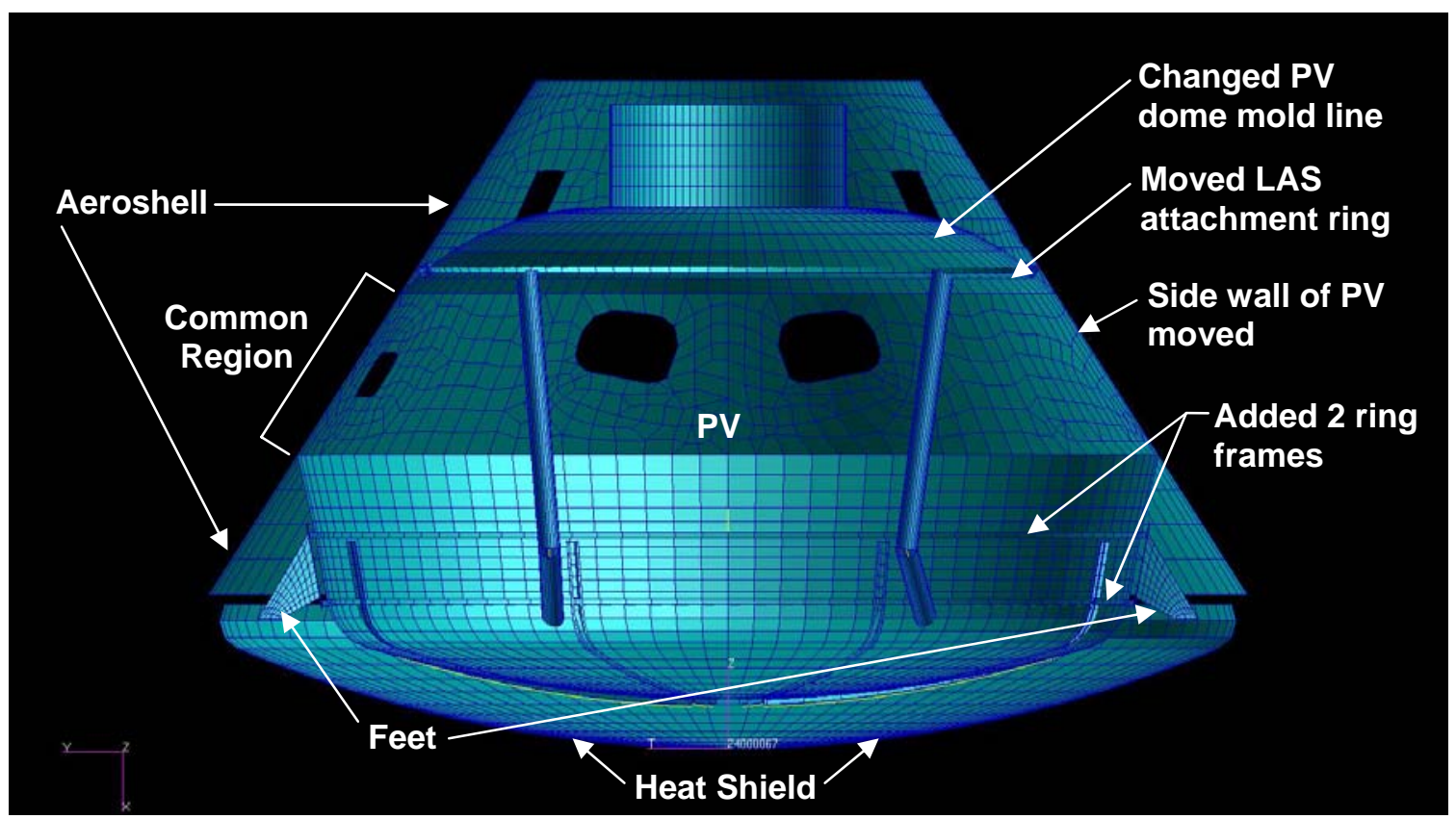

Figure 18.-Monocoque CM concept FEA model with alterations from the stiffened sandwich CM concept denoted.

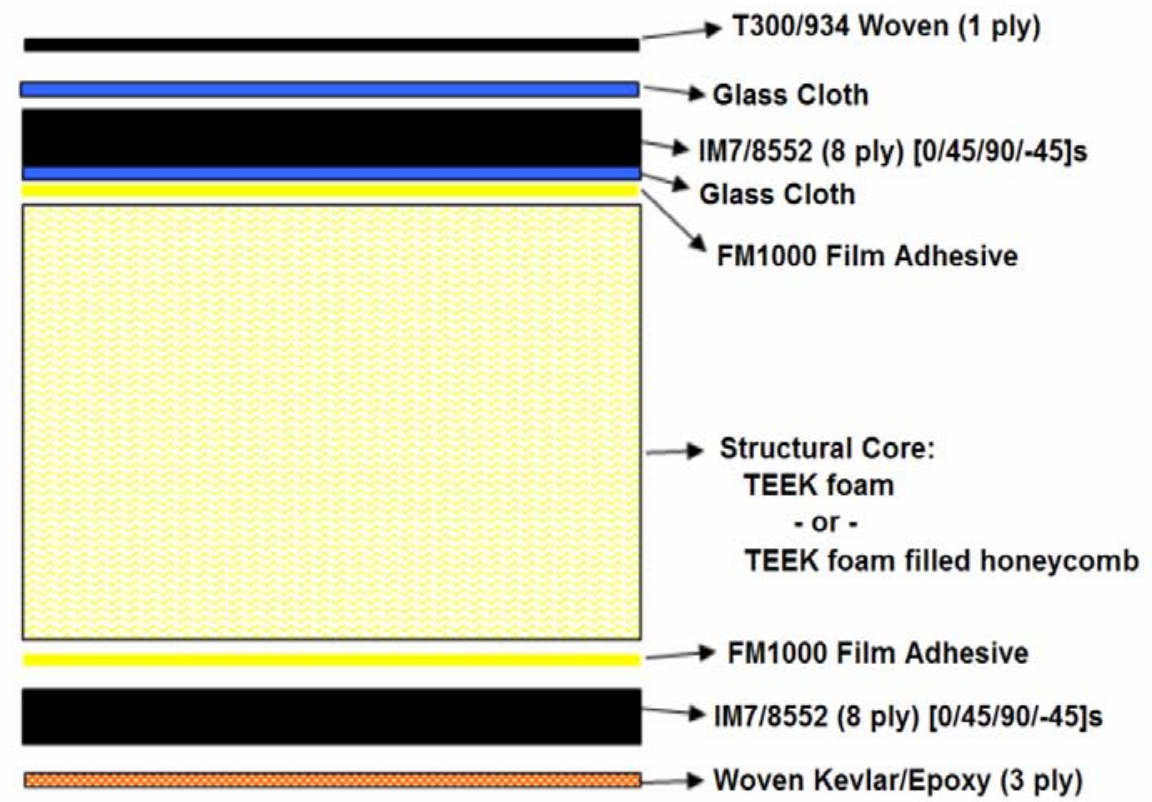

Figure 19.-Megasandwich panel construction considered for the monocoque CMconcept.

Figure 20 shows the margins of safety and controlling failure analysis for the monocoque CM concept panels with the megasandwich layup facesheets. Red areas of the margin of safety plot indicate panels with negative margins, signifying failure. Numbers within the colorbar legend indicate the number of components that fall within the associated range. The controlling failure analysis plot shows that a majority of the negative margins are caused by facesheet composite strength failure mechanisms, 


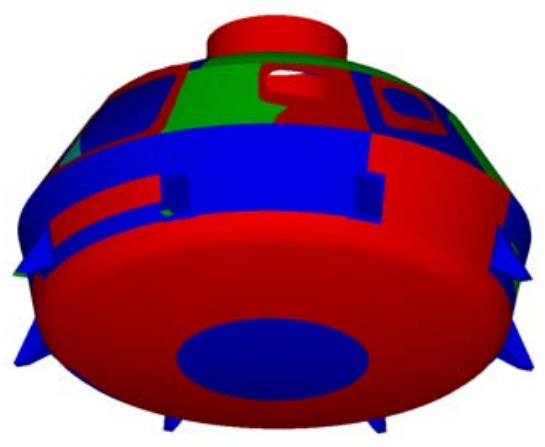

(a)

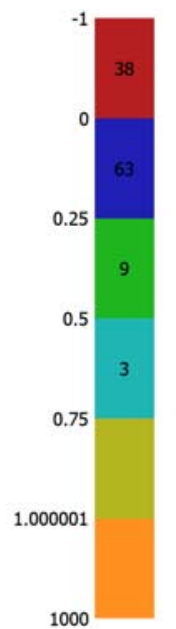

Analysis "Composite Strength, Tsai-Hahn Interaction", 2 components Analysis "Composite Strength, Tsai-Hill Interaction", 2 components posite Strength, Tsai-Wu Interaction", 24 comp Analysis "Shear Strength, $X$ (Longitudinal) direction $\{$ Hexcel\}", 65 components Analysis "Shear Strength, $Y$ (Transerse) direction (Hexcel)", 4 components [Analysis "Wrinkling, Eqn 1, Isotropic or Honeycomb Core, $X, Y$ \& Interaction"], 16 components H

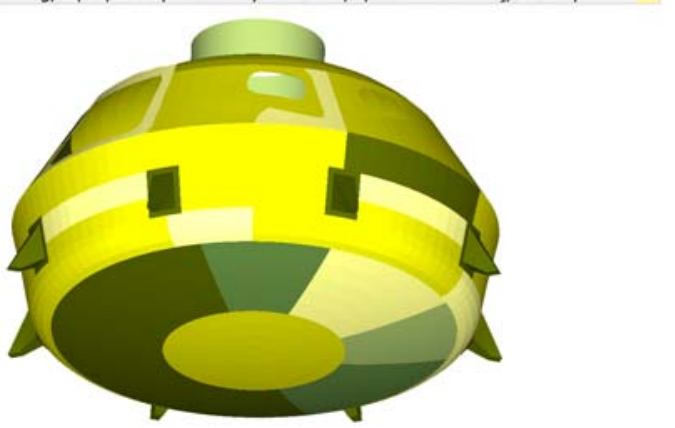

(b)

Figure 20.-(a) Margins of safety and (b) controlling failure analysis for the monocoque CM concept analyzed using the megasandwich facesheet layups. Note that the integers within the colorbar legend indicate the number of components that fall within the associated range.

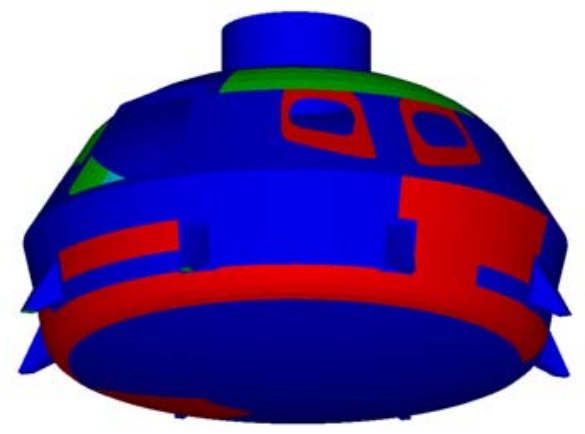

(a)

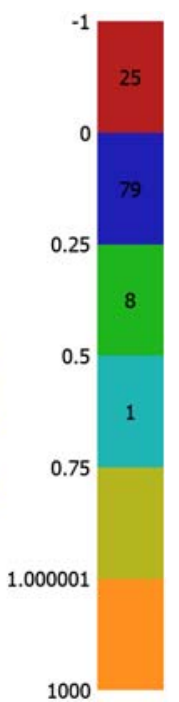

Analysis "Composite Strength, Tsai-Hahn Interaction", 1 component Analysis "Composite Strength, Tsai-Wu Interaction", 34 components Analysis "Shear Crimping, X, Y \& Interaction $\{$ Hexcel\}", 1 component Analysis "Shear Strength, $X$ (Longitudinal) direction $\{$ Hexcel\}", 70 components $\mathrm{H}$ Analysis "Shear Strength, $Y$ (Transverse) direction $\{$ Hexcel\}", 7 components H

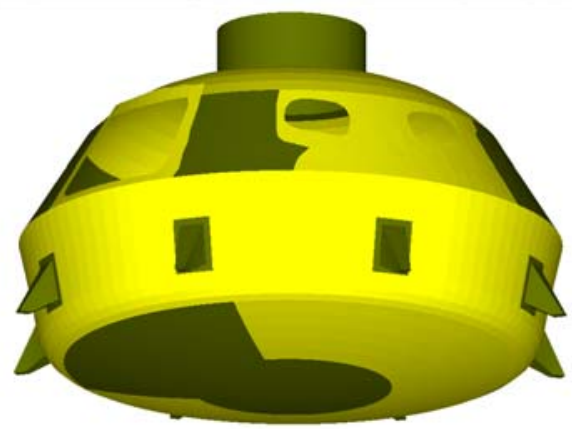

(b)

Figure 21.-(a) Margins of safety and (b) controlling failure analysis for the monocoque CM concept sized allowing the megasandwich facesheet layups to become thicker.

indicating that the proposed megasandwich facesheet layups are inadequate. In order to overcome these facesheet failures, the top and bottom facesheets were allowed to size to greater thicknesses. The top facesheet (see fig. 19), which was originally 0.0659 in. thick, was allowed to size to $1,1.5,2,2.5$, or 3 times its original thickness, while the bottom facesheet, which was originally 0.0557 in. thick, was allowed to size to 1, 1.5, 2, 2.5, 3, 3.5, 4, 4.5, or 5 times its original thickness. The resulting margins of safety and controlling failure analyses are shown in figure 21. As indicated by figure 21(a), there are still a number of panels with negative margins, but now the failure mechanism associated with these negative margins is panel core failure (see fig. 21(b)). Note that the maximum allowable core thickness for this sizing was 5 in, which is an approximate limit at which contact between the heat shield and PV would occur. 


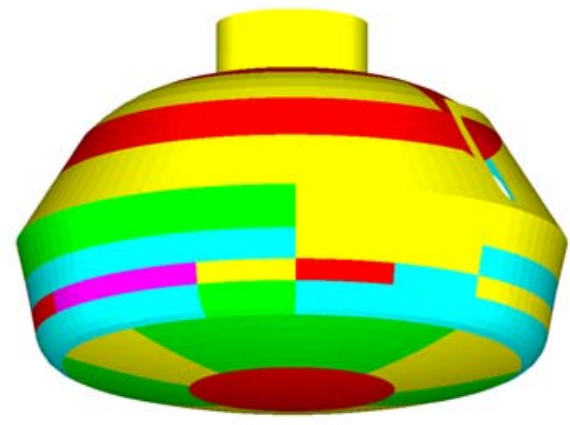

(a)

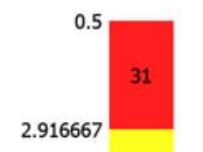

Foam "TEEK - 5 pcf", Density 0.0028935, Dry, 28 components Foam "TEEK - 8 pcf'" Density 0.0046296, Dry, 14 components [Foam "TEEK in Al Honeycomb", Density 0.002778 , Dry], 55 components

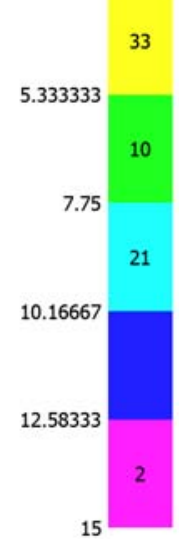

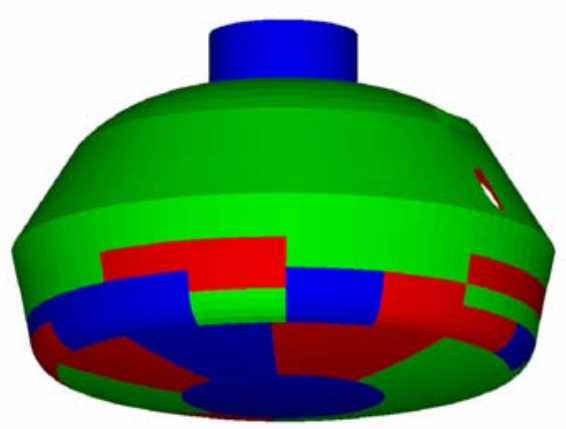

(b)

Figure 22.-(a) Core thickness (in.) and (b) TEEK core material required for all positive panel margins in the monocoque CM concept using the megasandwich construction.

To overcome these negative margins associated with core failure, the core was allowed to size to as thick as necessary to close the design (i.e., to provide positive margins in all PV panels). Figure 22(a) shows the required core thickness, while figure 22(b) shows the TEEK core material selected. With two panel components requiring core thicknesses of 15 in. and 33 out of 97 panel components requiring core thicknesses greater than 5.3 in., it is clear that the proposed megasandwich panel construction is impractical for application in the monocoque CM design. The beam and panel weights of this design, with its unrealistically thick panels, are given in table 9.

TABLE 9.-COMPARISON OF WEIGHTS FOR THE CLOSED MONOCOQUE CM CONCEPT DESIGNS

\begin{tabular}{|l|c|c|c|c|}
\hline \multicolumn{2}{|c|}{ Design } & \multicolumn{3}{c|}{} \\
\hline Panel facesheets & Panel core & $\begin{array}{c}\text { Beam weight, } \\
(\mathrm{lb})\end{array}$ & $\begin{array}{c}\text { Panel weight, } \\
(\mathrm{lb})\end{array}$ & $\begin{array}{c}\text { Total weight, } \\
(\mathrm{lb})\end{array}$ \\
\hline Megasandwich layups & TEEK & 136 & 1829 & 1965 \\
\hline Megasandwich layups & WebCore & 136 & 1402 & 1538 \\
\hline IM7/977-2 & WebCore & 136 & 945 & 1081 \\
\hline
\end{tabular}

In order to size a more practical monocoque CM, WebCore was substituted for the TEEK as the panel core material, and a new sizing performed. Starting with WebCore A, B, Light Bi, and Tycor G6 Bi (see table 3), it was found that core thicknesses of up to 8.5 in.were required to achieve a closed design. While this is lower than the $15 \mathrm{in}$. maximum core thickness required for the TEEK core panel design, it is still above the 5 in. maximum practical thickness. Thus, new WebCore Dense Bi core properties were obtained by extrapolating the properties and density of the Tycor G6 Bi core (see table 3). This is believed to represent an upper bound of the density for a WebCore material (ref. 10) with the properties given in table 3. The optimized core thicknesses and WebCore core materials are shown in figure 23. Note that all core thicknesses are within the $5 \mathrm{in}$. upper bound. The final weights of the beams and panels for this design are given in table 9.

As a final sizing study for the monocoque CM concept, IM7/977-2 graphite/epoxy facesheets were substituted for the megasandwich facesheets. This stronger material is more structurally efficient and allows a significantly lower panel weight for the CM, while the WebCore core thicknesses and materials are similar to those shown in figure 23. The final beam and panel weights for the IM7/977-2 facesheet panels are shown in table 9. Comparing the total weights of the three closed monocoque CM designs, it is clear that the introduction of both the WebCore core material and the IM7/977-2 facesheets save a 


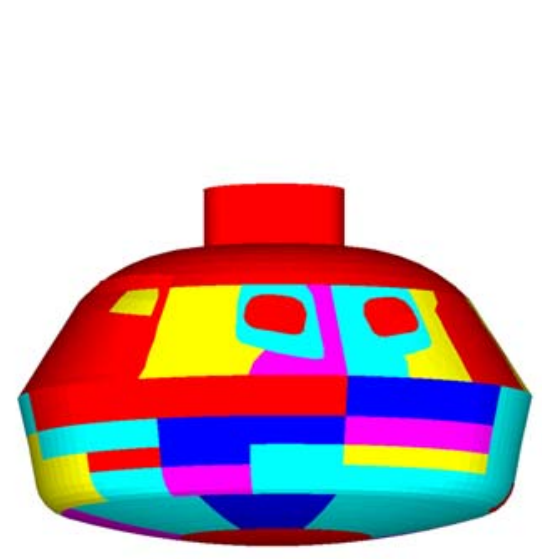

(a)

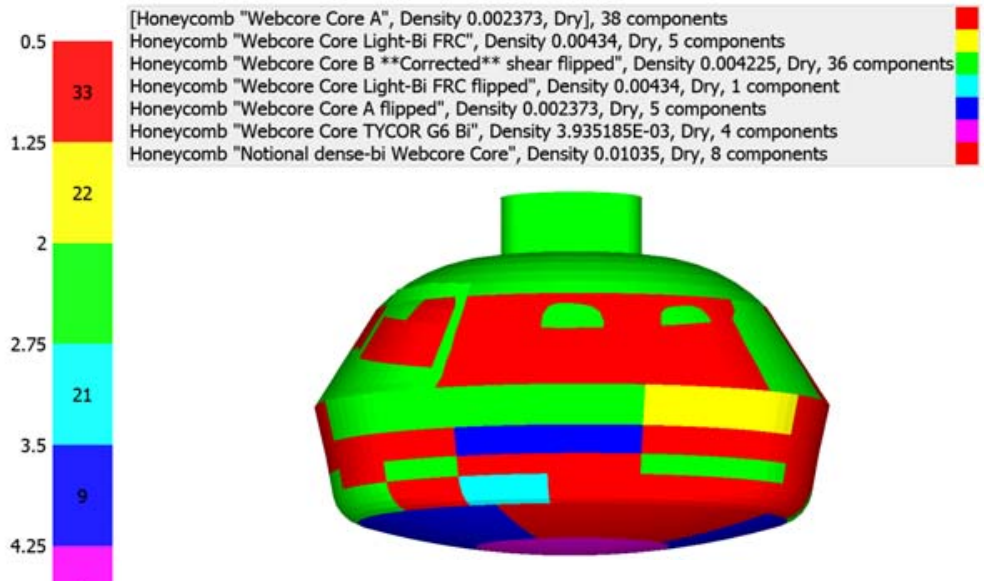

(b)

Figure 23.-(a) Core thickness (in.) and (b) WebCore core material required for all positive panel margins in the monocoque $\mathrm{CM}$ concept using the megasandwich facesheet layups.

significant amount of weight. It should be noted that optimization of the shape of the monocoque PV was not performed, and this could save additional weight, especially in the vicinity of the lower shoulder where large out-of-plane loads are present in the current monocoque PV design.

\section{Geometrically Stiffened CM Concept}

The geometrically stiffened CM concept (see fig. 2(c)) was developed by NASA Ames Research Center personnel (ref. 11) based on the idea of utilizing a corrugated PV shell to provide the stiffness required to carry the loads. The original concept involved a nearly completely solid laminate PV, with a predominantly aluminum honeycomb sandwich aeroshell. A quarter symmetry FEA model was provided by NASA Ames (refs. 2 and 11), which is shown is figure 24, with three load cases considered: internal pressure, 15g LAS pad abort, and 16g late abort decent (see tables 1 and 2). Three cases for the geometrically stiffened CM concept were sized: (1) the baseline case, consisting of a mainly IM7/977-2 solid laminate PV (see fig. 24), (2) a predominantly metallic ( $\mathrm{Al}$ or $\mathrm{Ti}$ ) honeycomb sandwich design with IM7/977-2 laminate facesheets, wherein the honeycomb sandwich was substituted for most solid laminate regions, and (3) a predominantly WebCore sandwich design with IM7/977-2 laminate facesheets, wherein WebCore was substituted for the honeycomb sandwich. The aeroshell was sized, but the heat shield, which was present in the FEA model was not (legacy Smart Buyer Team heat shield was assumed). Note that only one beam component is present in the geometrically stiffened CM concept design, a ring at the top of the PV tunnel.

Figure 24 shows the solid laminate thickness for the closed baseline geometrically stiffened CM design. For the magenta regions in the figure, which are honeycomb sandwich panels, the thin top facesheet thickness is plotted. The figure indicates that most of the PV has sized to a reasonable thickness below 0.411 in., but in the lower shoulder region, a major portion of the PV has sized to thicknesses between 0.619 and 0.722 in. Figure 25 shows the metallic honeycomb core thickness, as well as the controlling load case for the geometrically stiffened CM concept. Due to large out-of-plane shear loads, the small honeycomb sandwich transition region in the floor of the PV (shown as red in fig. 25(a)) has sized to a core thickness of 5 in., which could be problematic in terms of the transition from solid laminate. The final optimized weight for the baseline (mainly solid laminate) geometrically stiffened CM is shown in table 10. It is noted that, when the geometrically stiffened CM concept was sized using only a max. strain laminate failure criterion in combination with FEA loads, a weight of approximately $1500 \mathrm{lbs}$ was determined. By utilizing HyperSizer's array of laminate, sandwich panel, and buckling failure checks, a more realistic weight (1850 lbs) has been determined. 


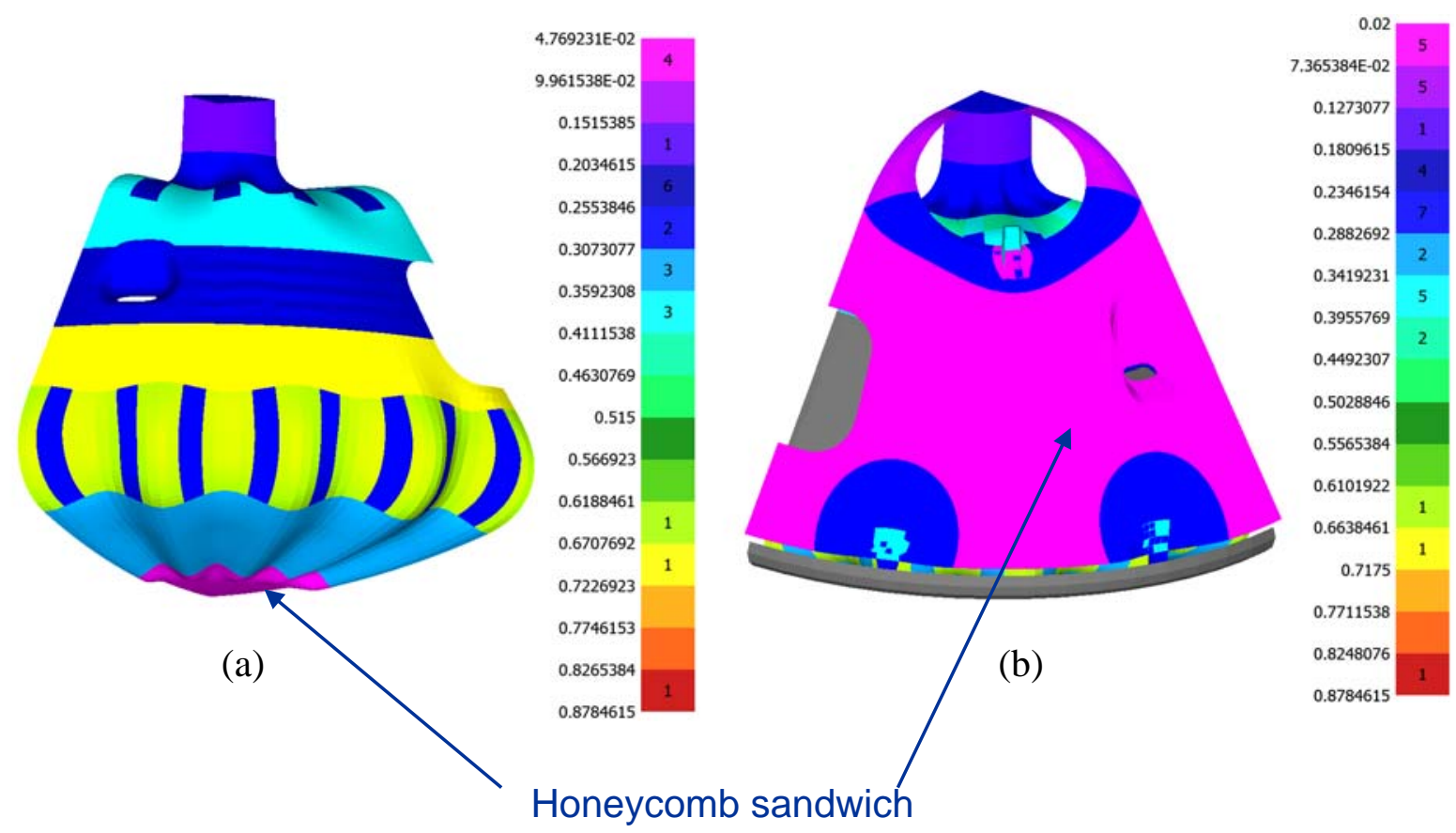

Figure 24.-Quarter symmetry FEA model for the geometrically stiffened CM concept. Laminate thickness (in.) are plotted for (a) the PV without the aeroshell and (b) the aeroshell on the PV. The baseline configuration regions composed of honeycomb sandwich are shown in magenta, while the remainder of the acreage is solid laminate. Note that the single 0.878 in. thick component (as indicated by the " 1 " in the final, red colorbar range) is a small pad that is not visible in the figures.

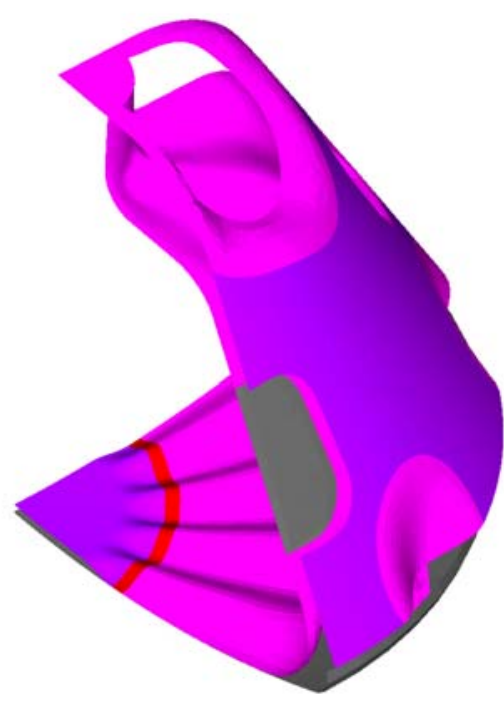

(a)
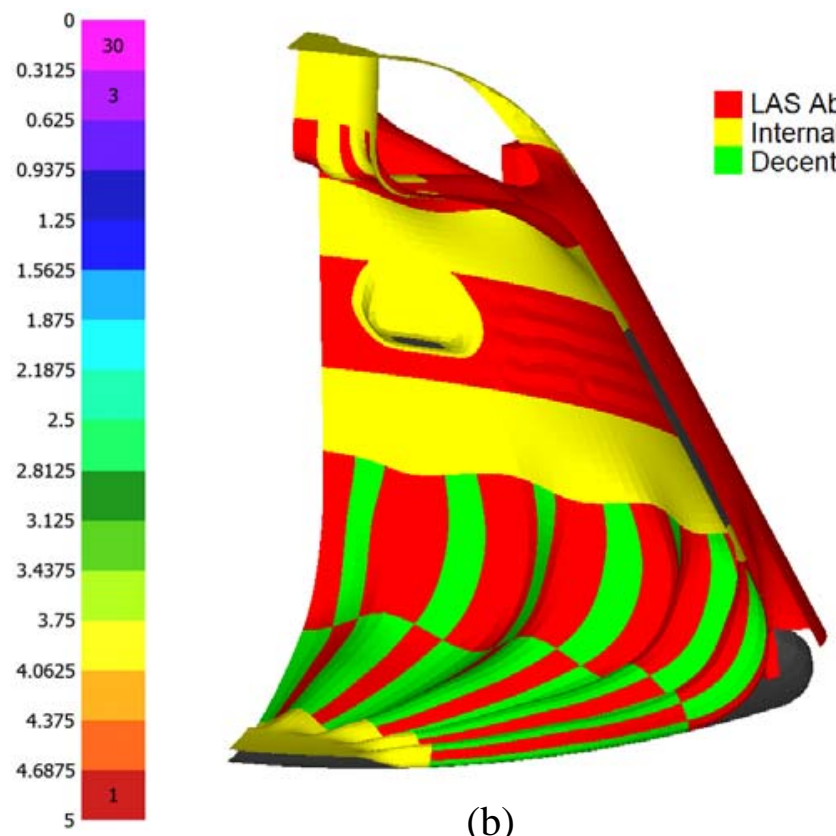

(b)

Figure 25.-(a) Metallic honeycomb core thickness (in.) and (b) controlling load case for the baseline (mainly solid laminate) geometrically stiffened CM concept. 


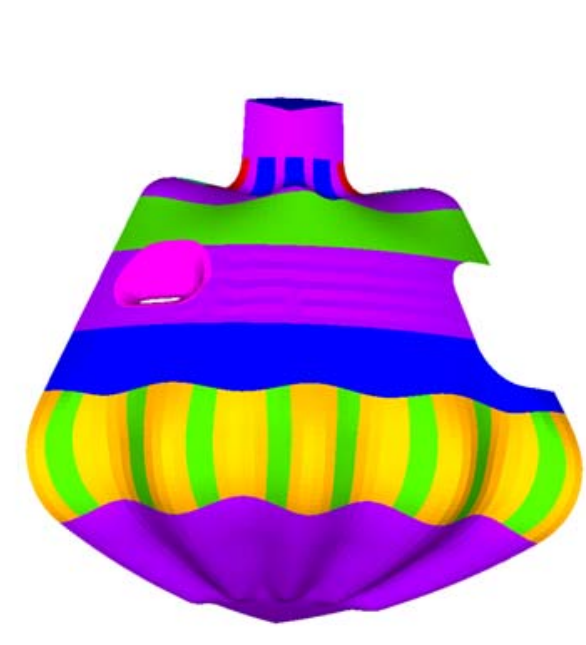

(a)
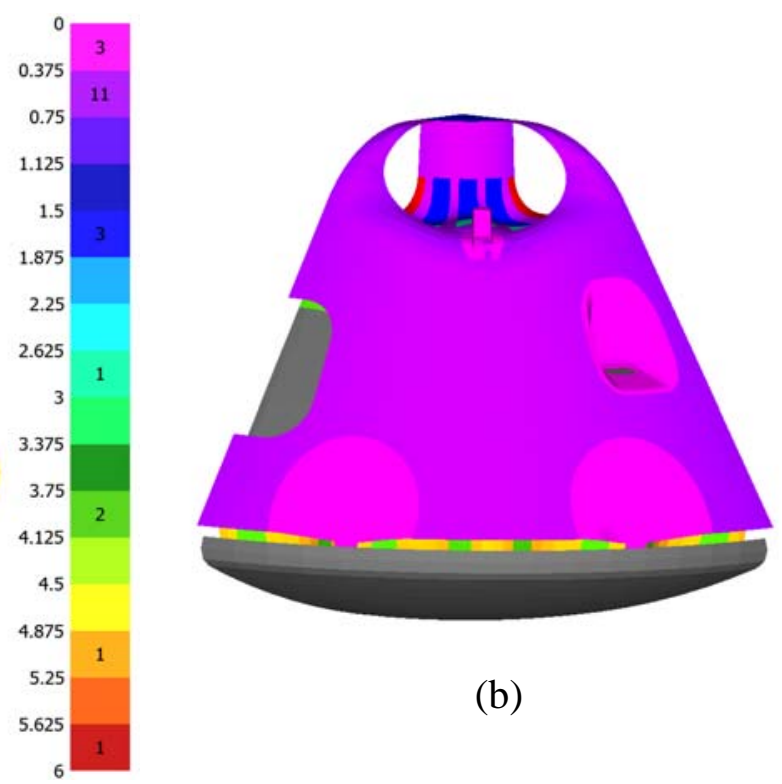

(b)

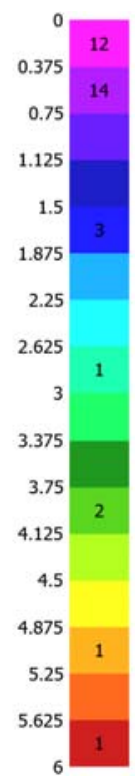

Figure 26.-Metallic honeycomb core thickness (in.) for the predominantly honeycomb sandwich geometrically stiffened CM concept for (a) the PV without the aeroshell and (b) the aeroshell on the PV.

When metallic honeycomb sandwich panels are substituted for the solid laminate PV acreage, the optimized core thicknesses plotted in figure 26 result. The thick (6 in.) core required on the model edges at the PV tunnel neck are due to high out-of-plane shear loads in this region. $5 \mathrm{in}$. core is also required in the corrugated lower shoulder region due to high out-of-plane shear loads. It is also noteworthy that the region in the floor bottom that required a $5 \mathrm{in}$. core in the mainly solid laminate design (see fig. 25(a)) now requires only a $0.5 \mathrm{in}$. core (see fig. 26(a)). This significant change is due to the fact that the transition from solid laminate to honeycomb that previously induced the large out-of-plane loads in this region has now been removed. The final weight for the sized geometrically stiffened CM concept with predominantly metallic honeycomb sandwich panels is shown in table 10. Data both with and without adhesive weight, which accounts for bonding between the core and the facesheets, are shown.

Figure 27 shows the sized core thicknesses for WebCore panels in the geometrically stiffened CM concept. Comparing figures 26(a) and 27(a), it appears that the core thickness of certain regions decrease (e.g., the corrugated lower shoulder), while the core thickness of other regions increases (e.g., the floor). These thicknesses translate into weight as shown in figure 28, which compares the panel unit weights for the metallic honeycomb and WebCore PV designs. As discussed in section II.C, the benefits of WebCore compared to metallic honeycomb core are quite dependent on the character of panel loading in a given region.

The final weight of the WebCore geometrically stiffened CM concept is compared to the other cases examined in table 10. It is clear that the introduction of sandwich panels for the geometrically stiffened PV has the potential to save a significant amount of weight compared to the mainly solid laminate design. In addition, the metallic honeycomb sandwich design provides a somewhat lower weight than the WebCore sandwich design when adhesive weight is neglected, and slightly higher when adhesive weight is included. This is similar to the trend observed in the stiffened sandwich CM concept trade studies (see tables 7 and 8). It is clear that WebCore is competitive with the metallic honeycomb design. It is likely that the absolute weight optimized design would be a hybrid design, including solid laminate, metallic honeycomb, and WebCore panels in different locations. 


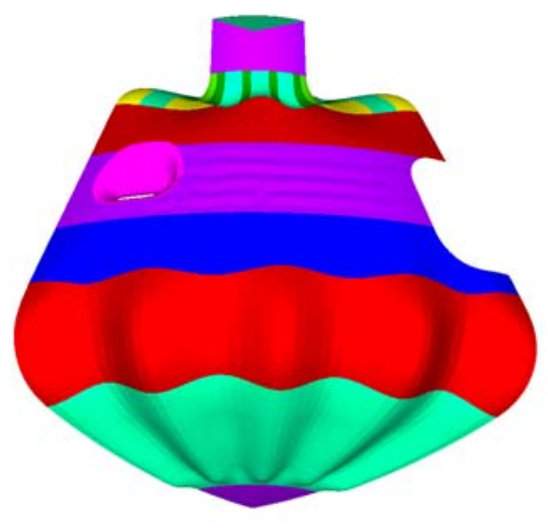

(a)
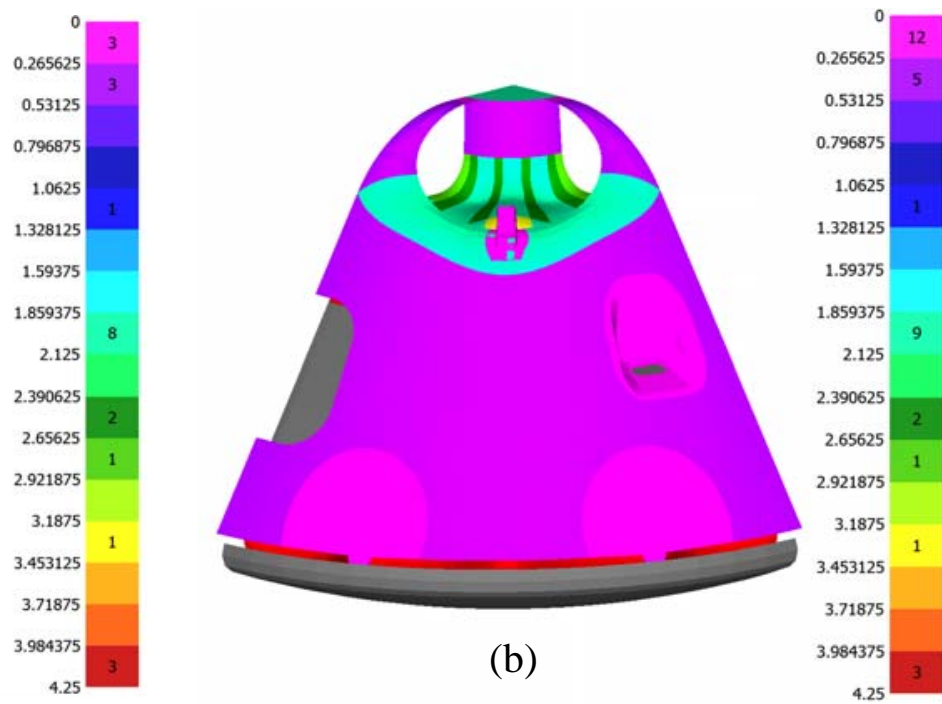

Figure 27.-WebCore core thickness (in.) for the predominantly WebCore sandwich geometrically stiffened $\mathrm{CM}$ concept for (a) the PV without the aeroshell and (b) the aeroshell on the PV.

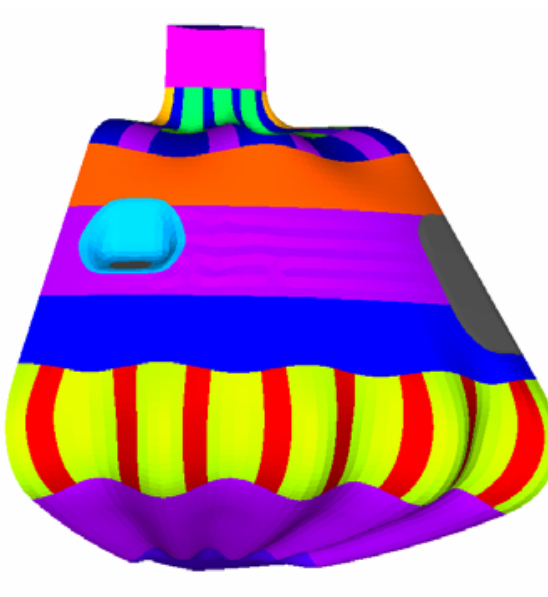

(a)

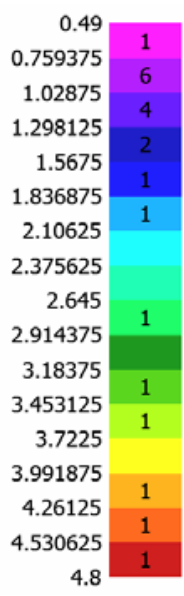

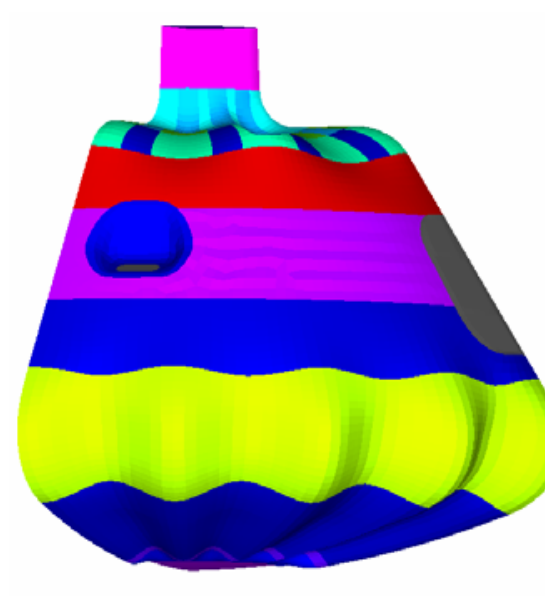

(b)

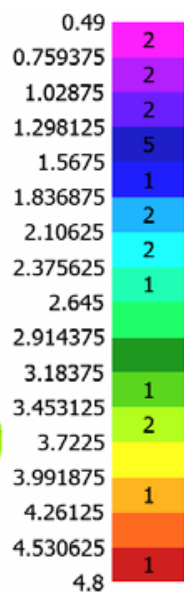

4.8

Figure 28.-Comparison of unit weights (psf) for the (a) metallic honeycomb and (b) WebCore sandwich panel geometrically stiffened CM concept.

TABLE 10.-COMPARISON OF WEIGHTS (LB) FOR THE GEOMETRICALLY STIFFENED CM CONCEPT DESIGNS

\begin{tabular}{|l|c|c|c|c|}
\hline & $\begin{array}{c}\text { Adhesive weight, } \\
(\mathrm{psf})\end{array}$ & $\begin{array}{c}\text { PV weight, } \\
(\mathrm{lb})\end{array}$ & $\begin{array}{c}\text { Aeroshell weight, } \\
(\mathrm{lb})\end{array}$ & $\begin{array}{c}\text { Total weight, } \\
(\mathrm{lb})\end{array}$ \\
\hline Solid laminate & 0 & 1582 & 268 & 1850 \\
\hline Metallic honeycomb sandwich & 0 & 937 & 270 & 1216 \\
\hline Metallic honeycomb sandwich & 0.2 & 1038 & 313 & 1351 \\
\hline WebCore sandwich & 0 & 1040 & 280 & 1330 \\
\hline
\end{tabular}




\section{Conclusion}

Preliminary structural sizing and alternative material trade studies have been conducted for three CM concepts included in the 2006 NESC composite CM project using the HyperSizer automated structural sizing software. These three CM concepts were stiffened sandwich, monocoque, and geometrically stiffened designs. Load cases involving internal pressure, as well as inertial loads due to accelerations, were considered. The objective of the studies was to trade different materials and panel concepts within each CM concept in order to determine the weight benefits of these materials. Towards this end, DRA was introduced as both a panel facesheet material and a beam material for the stiffened sandwich concept, while WebCore panels were introduced for all three CM concepts. Comparisons among the CM concepts (based on the analyses herein as well as analyses conducted by other NESC composite CM team members) are presented in reference 2 and not discussed in the present paper.

For the stiffened sandwich CM concept, it was found that WebCore sandwich panels are competitive with aluminum honeycomb panels, providing a small weight savings in both a representative acreage panel sizing study and a sizing of the entire PV. DRA was found to be significantly heavier than the IM7/977-2 composite for both sandwich panel facesheets and beams, but somewhat lighter than aluminum alloys in both cases. As such, DRA can be viewed as a middle ground between the metallic aluminum alloy and the graphite/epoxy composite, still providing some weight savings, but allowing the CM to remain similar to the Smart Buyer Team metallic design. In addition, DRA is likely to be significantly less expensive to manufacture compared to the graphite epoxy and may be considered to be a lower risk technology.

For the monocoque CM concept, it was found that the original panel concept associated with the monocoque design (the "megasandwich"), which was conceived with MMOD impact resistance in mind, was not structurally viable. Not only were the megasandwich facesheets insufficient to carry the PV in-plane loads, but very thick (up to 15 in.) panels would be required to carry the out-of-plane shear loads. Allowing the original megasandwich facesheets to size up and substituting WebCore in place of the megasandwich TEEK foam core provided a significant (22 percent) weight savings in the design. Then, substituting IM7/977-2 facesheets provided and additional 30 percent weight savings.

Finally, for the geometrically stiffened CM concept, it was found that a closed design is possible utilizing the baseline mainly solid laminate PV design. However, significant weight savings are possible by introducing sandwich panels for the PV acreage. A comparison of an optimized metallic honeycomb PV design with an optimized WebCore sandwich panel design indicated that the final weights are quite similar, but with a good deal of variation over the geometry in terms of which concept provides the lower local unit weight. As such, it would appear that a hybrid design, combining solid laminate, metallic honeycomb sandwich, and WebCore sandwich panels would provide the lightest weight solution.

\section{References}

1. Baccus, R., CEV Reference Configuration Design Definition Document, C.P.O. Johnson Space Center, Document No.: CxP 72103, 2006.

2. Kirsch, M., Gates, T., Alexandrov, N., Arnold, S., Bednarcyk, B., Feldhaus, W., Miura, H., Fernandez, I., Paddock, D., Nettles, A., Crowdsely, M., Sleight, D., Pelham, L., Jackson, K., Grunsfeld, J., and MacConnell, J., "Composite Crew Module (CM) Pressure Vessel Assessment Phase I Technical Report,” NASA NESC Report, 2007.

3. HyperSizer Structural Sizing Software, Collier Research Corp., Hampton, VA, http://www.hypersizer.com, 2006.

4. NEi NASTRAN, Noran Engineering, Inc., Westminster, CA, http://www.nenastran.com/.

5. HyperFEA, Collier Research Corp., Hampton, VA, http://www.hypersizer.com/documents/brochure_ HyperFEA.pdf, 2007.

6. DWA Aluminum Composites, Chatsworth, CA, http://www.dwa-dra.com/. 
7. Stoll, F., Day, S., Campbell, S., Banerjee, R., Sheppard, M., and Lang, E., “Advancements in Engineered Composite Sandwich Core Materials,” SAMPE 2006, May, Long Beach, CA, 2006.

8. WebCore Technologies, Inc., Miamisburg, OH, http://www.webcoreonline.com/.

9. Stokes, E., "Hydrogen Permeability of Polymer Based Composites under Bi-axial Strain and Cryogenic Temperatures,” 45th AIAA/ASME/ASCE/AHS/ASC Structures, Structural Dynamics, and Materials Conference. AIAA-2004-1858, 2004.

10. Sheppard, M., Personal Communication, WebCore Technologies, Inc., July, 2006.

11. Fernandez, I., and Miura, H., Personal Communication, NASA Ames Research Center, August, 2006. 


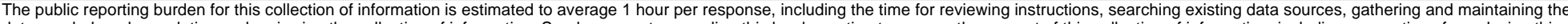

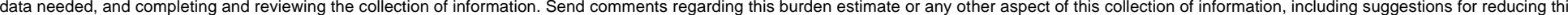

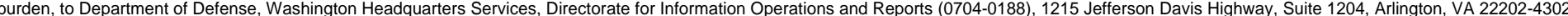

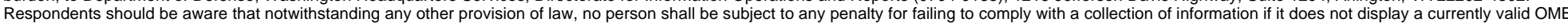
control number.

PLEASE DO NOT RETURN YOUR FORM TO THE ABOVE ADDRESS

\section{REPORT DATE (DD-MM- $Y Y Y Y)$ \\ 2. REPORT TYPE \\ 3. DATES COVERED (From - To)}

01-08-2007

\section{TITLE AND SUBTITLE}

Technical Memorandum

Preliminary Structural Sizing and Alternative Material Trade Study of CEV Crew Module

6. AUTHOR(S)

Bednarcyk, Brett, A.; Arnold, Steven, M.; Collier, Craig, S.; Yarrington, Phillip, W.

5a. CONTRACT NUMBER

5b. GRANT NUMBER

5c. PROGRAM ELEMENT NUMBER

\section{5d. PROJECT NUMBER}

5e. TASK NUMBER

5f. WORK UNIT NUMBER

WBS 843515.02.01.03.05.08.03

\section{PERFORMING ORGANIZATION NAME(S) AND ADDRESS(ES)}

National Aeronautics and Space Administration

8. PERFORMING ORGANIZATION

REPORT NUMBER

John H. Glenn Research Center at Lewis Field

E-16119

Cleveland, Ohio 44135-3191

\section{SPONSORING/MONITORING AGENCY NAME(S) AND ADDRESS(ES)}

National Aeronautics and Space Administration

Washington, DC 20546-0001

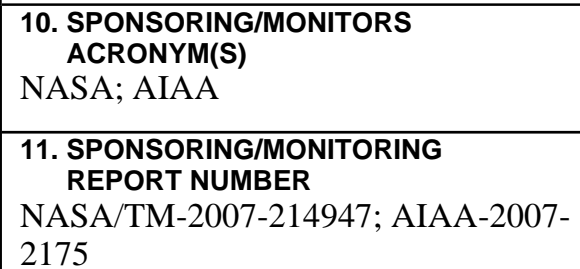

\section{DISTRIBUTIONIAVAILABILITY STATEMENT}

Unclassified-Unlimited

Subject Categories: 18, 24, and 39

Available electronically at http://gltrs.grc.nasa.gov

This publication is available from the NASA Center for AeroSpace Information, 301-621-0390

\section{SUPPLEMENTARY NOTES}

\section{ABSTRACT}

This paper presents the results of a preliminary structural sizing and alternate material trade study for NASA's Crew Exploration Vehicle (CEV) Crew Module (CM). This critical CEV component will house the astronauts during ascent, docking with the International Space Station, reentry, and landing. The alternate material design study considers three materials beyond the standard metallic (aluminum alloy) design that resulted from an earlier NASA Smart Buyer Team analysis. These materials are graphite/epoxy composite laminates, discontinuously reinforced SiC/Al (DRA) composites, and a novel integrated panel material/concept known as WebCore. Using the HyperSizer (Collier Research and Development Corporation) structural sizing software and NASTRAN finite element analysis code, a comparison is made among these materials for the three composite CM concepts considered by the 2006 NASA Engineering and Safety Center Composite Crew Module project.

\section{SUBJECT TERMS}

Design; Sizing; CEV; Crew Module; Orion; Spacecraft; Structures; Composite; Discontinuously reinforced aluminum; WebCore; HyperSizer

\begin{tabular}{|c|c|c|c|c|}
\hline \multicolumn{3}{|c|}{ 16. SECURITY CLASSIFICATION OF: } & \multirow{2}{*}{$\begin{array}{l}\text { 17. LIMITATION OF } \\
\text { ABSTRACT } \\
\text { UU }\end{array}$} & \multirow{2}{*}{$\begin{array}{l}\text { 18. NUMBER } \\
\text { OF } \\
\text { PAGES } \\
31\end{array}$} \\
\hline $\begin{array}{l}\text { a. REPORT } \\
\mathrm{U}\end{array}$ & $\begin{array}{l}\text { b. ABSTRACT } \\
U\end{array}$ & $\begin{array}{l}\text { c. THIS } \\
\text { PAGE } \\
\text { U }\end{array}$ & & \\
\hline
\end{tabular}



